\title{
THE ROLE OF AMP-ACTIVATED PROTEIN KINASE IN ADIPOSE TISSUE METABOLISM AND INFLAMMATION
}

\section{Silvia Bijland*, Sarah Jane Mancini and lan Paul Salt}

Institute of Cardiovascular \& Medical Sciences, College of Medical, Veterinary and Life Sciences, University of Glasgow, Glasgow, G12 8QQ, United Kingdom

${ }^{*}$ These authors contributed equally to this review

Key words: adipose, AMP-activated protein kinase, AMPK, obesity, diabetes, inflammation

Short title: AMP-activated protein kinase in adipose

Corresponding author: Dr lan P. Salt, Institute of Cardiovascular \& Medical Sciences, College of Medical, Veterinary and Life Sciences, University of Glasgow, Glasgow, G12 $8 Q Q$, United Kingdom

Tel: 0141330 2049; Fax: 0141330 5481; email: ian.salt@glasgow.ac.uk

Abbreviations: ACC, acetyl CoA carboxylase; AICAR, 5'-Aminoimidazole-4-carboxamide ribonucleoside; AMPK, AMP-activated protein kinase; aP2, adipocyte-specific fatty acid binding protein; ATGL, adipose triglyceride lipase; BAT, brown adipose tissue; CaMKK $\beta, \mathrm{Ca}^{2+} / \mathrm{calmodulin}$-dependent protein kinase kinase $\beta$; CBS, cystathionine- $\beta$ synthase; C/EBP, CCAAT/enhancer binding protein; CGI-58, comparative gene identification-58; CPT1, carnitine palmitoyltransferase I; DAG, diacylglycerol; FA, fatty acid; FAS, fatty acid synthase; GLUT4, glucose transporter 4; HSL, hormone-sensitive lipase; IL, interleukin; IRS-1, insulin receptor substrate-1; JNK, c-Jun N-terminal kinase; LKB1, liver kinase B1; LPL, lipoprotein lipase; MAG, monoacylglycerol; MCP-1, monocyte chemoattractant protein-1; MIP-1, macrophage inflammatory protein-1; mTOR, mammalian target of rapamycin; $\mathrm{NF}_{\kappa \mathrm{B}}$, nuclear factor $\kappa \mathrm{B}$; p90RSK, p90 ribosomal $\mathrm{S} 6$ kinase, PDE3B, phosphodiesterase 3B; PGC-1 $\alpha$, peroxisome proliferator-activated receptor- $\gamma$ coactivator-1 $\alpha$; PI3K, phosphatidylinositol 3'kinase; PKA, CAMP-dependent protein kinase; PKB, protein kinase B; PPAR, peroxisome proliferator-activated receptor; Pref-1, preadipocyte factor-1; PVAT, perivascular adipose tissue; Rab-GAP, Rab GTPaseactivating protein; RANTES, regulated and normal T cell expressed and secreted; SCAT, subcutaneous adipose tissue; SCD1, stearoyl-CoA desaturase 1; SGK1, serum- and glucocorticoid-induced protein kinase; SREBP-1c, sterol regulatory element binding protein 1c; TAG, triacylglyceride; TLR, toll-like receptor; TNF- $\alpha$, tumour necrosis factor- $\alpha$; UCP1; uncoupling protein 1; VAT, visceral adipose tissue; WAT, white adipose tissue. 


\section{SUMMARY}

AMP-activated protein kinase (AMPK) is a key regulator of cellular and whole body energy balance. AMPK phosphorylates and regulates many proteins concerned with nutrient metabolism, largely acting to suppress anabolic ATP-consuming pathways whilst stimulating catabolic ATP-generating pathways. This has led to considerable interest in AMPK as a therapeutic target for the metabolic dysfunction observed in obesity and insulin resistance. The role of AMPK in skeletal muscle and the liver has been extensively studied, such that AMPK has been demonstrated to inhibit synthesis of fatty acids, cholesterol and isoprenoids, hepatic gluconeogenesis and translation whilst increasing fatty acid oxidation, muscle glucose transport, mitochondrial biogenesis and caloric intake. The role of AMPK in the other principal metabolic and insulin-sensitive tissue, adipose, remains poorly characterised in comparison, yet increasing evidence supports an important role for AMPK in adipose tissue function. Obesity is characterised by hypertrophy of adipocytes and the development of a chronic sub-clinical proinflammatory environment in adipose tissue, leading to increased infiltration of immune cells. This combination of dysfunctional hypertrophic adipocytes and a proinflammatory environment contributes to insulin resistance and the development of type 2 diabetes. Exciting recent studies indicate that AMPK may not only influence metabolism in adipocytes but also act to suppress this proinflammatory environment, such that targeting AMPK in adipose tissue may be desirable to normalise adipose dysfunction and inflammation. In this review we discuss the role of AMPK in adipose tissue, focussing on the regulation of carbohydrate and lipid metabolism, adipogenesis and proinflammatory pathways in physiological and pathophysiological conditions.

\section{INTRODUCTION}

AMP-activated protein kinase (AMPK) is the downstream component of a protein kinase cascade that has a central role in the regulation of energy balance at both the cellular and whole body level. As a consequence, AMPK activation is proposed to be a therapeutic target for the treatment of obesity and type 2 diabetes [1-3]. In addition to the metabolic actions of AMPK, increasing evidence suggests that AMPK has antiinflammatory actions, independent of its effects on carbohydrate and lipid metabolism [4]. Although the role of AMPK in liver and muscle is relatively well-characterised and have been reviewed extensively elsewhere [1-3], the role of AMPK in the other principal metabolic tissue, adipose, remains less well defined. The relative lack of data concerning the role of AMPK in adipose tissue may reflect the heterogeneity of adipose tissue and the marked difficulty in using standard molecular biology techniques to specifically up- and downregulate AMPK in terminally-differentiated adipocytes when compared to skeletal muscle and the liver. Dysfunctional metabolism and a chronic sub-clinical proinflammatory environment are observed in the adipose tissue of obese individuals, which contribute to the development of systemic insulin resistance and type 2 diabetes [5]. Given the metabolic and anti-inflammatory actions of AMPK activation, understanding the role(s) of AMPK in adipose tissue is, therefore, of significant importance. The focus of the current review is to examine the evidence concerning the actions of AMPK in adipose tissue and how these actions may impact on the whole body in the physiological and pathophysiological setting.

\section{ADIPOSE TISSUE PHYSIOLOGY \\ Adipose tissue composition and function}

At the whole body level, adipose tissue is divided into subcutaneous (SCAT) and visceral (VAT) depots. Adipose tissue contains several cell types, including adipocytes, immune cells, fibroblasts and preadipocytes, which can differentiate into mature adipocytes. Furthermore, adipose tissue contains cells from the vascular and nervous 
systems [6]. The heterogeneity of adipose tissue is complicated further by the classification of adipose tissue as white adipose tissue (WAT) or brown adipose tissue (BAT). Adipocytes within WAT serve to store excess dietary calories as triacylglyceride (TAG), whereas adipocytes within BAT allow energy dissipation by thermogenesis. In addition to its key role in lipid metabolism, WAT also has an endocrine action, secreting a large number of proteins, collectively termed adipocytokines, which influence systemic and local metabolism and inflammatory pathways. WAT represents the major proportion of adipose tissue in humans, although there is increasing evidence that BAT is present in significant quantities and co-exists with WAT within the same depot $[6,7]$.

White adipocytes contain a single lipid droplet of TAG that is formed from the esterification of fatty acids (FAs) and glycerol-3-phosphate. FAs are obtained from circulating lipoproteins by lipoprotein lipase (LPL)-mediated lipolysis and transported into the adipocyte or synthesised de novo by lipogenesis from non-lipid substrates such as glucose [8]. In the fasted state, or during prolonged physical activity, TAG in the lipid droplet is hydrolysed to fatty acids and glycerol, for use by other tissues for ATP generation or hepatic gluconeogenesis respectively. Insulin is the principal stimulus of TAG formation in white adipocytes, stimulating glucose transporter-4 (GLUT4)-mediated glucose transport and the activity of acetyl CoA carboxylase (ACC), the rate-limiting step of fatty acid synthesis from acetyl CoA [9]. In contrast, adrenergic stimulation of adipose tissue stimulates the formation of the second messenger CAMP, with subsequent activation of cAMP-dependent protein kinase (PKA) [8]. PKA phosphorylates and activates hormone-sensitive lipase (HSL), stimulating lipolysis. Insulin, via PKB (protein kinase B, also known as Akt)-mediated phosphorylation and activation of phosphodiesterase $3 \mathrm{~B}$ (PDE3B), stimulates breakdown of cAMP, thereby suppressing lipolysis [8].

Brown adipocytes contain multilocular lipid droplets and high numbers of mitochondria. The mitochondria in brown adipocytes characteristically express uncoupling protein 1 (UCP1), which uncouples ATP synthesis from substrate oxidation, allowing thermogenesis, yet the exact role of BAT in human energy balance remains uncertain $[6,7]$.

\section{Adipose tissue and obesity}

The rising incidence of type 2 diabetes is closely associated with the increased prevalence of obesity, particularly expansion of VAT rather than SCAT depots [10]. Chronic overfeeding leads to hypertrophy of adipocytes and the development of a chronic sub-clinical proinflammatory environment [5]. As a consequence, infiltration of adipose tissue with macrophages and other leukocytes occurs, which further exacerbates the proinflammatory environment in parallel with increasing insulin resistance of adipocytes [5]. The capacity of the dysfunctional adipocytes to store triglycerides becomes impaired, leading to ectopic storage of lipid in tissues including the liver and skeletal muscle [5]. Increased circulating adipose-derived proinflammatory cytokines, FAs and metabolites of this ectopic lipid subsequently impair insulin sensitivity in target tissues [5]. This may include cardiovascular tissues as a thin layer of adventitia-associated perivascular adipose tissue (PVAT) found in small arteries and arterioles also becomes dysfunctional in obesity and type 2 diabetes [11]. Targeting WAT to reduce inflammation has therefore received interest as a potential therapeutic target to limit the development of insulin resistance and type 2 diabetes. Furthermore, It has been hypothesised that targeting BAT to increase energy expenditure might be useful clinically for anti-obesity therapies [7].

\section{AMPK}

\section{Structure \& Regulation}

Since its initial characterisation as a protein kinase activity activated by AMP [12], significant advances have been made in understanding the enzymology of AMPK and 
these have been reviewed recently elsewhere [2]. Briefly, AMPK is a heterotrimeric complex of catalytic $\alpha$ and regulatory $\beta$ and $\gamma$ subunits. Several subunit isoforms of each subunit $(\alpha 1, \alpha 2, \beta 1, \beta 2, \gamma 1, \gamma 2$ and $\gamma 3$ ) have been identified in mammals, such that 12 theoretically possible complexes may be formed. The isoforms exhibit differential tissue expression and may influence subcellular localisation of the resultant AMPK complex $[13,14]$. AMPK is subject to regulation by allosteric mechanisms, and post-translational modifications including phosphorylation, myristoylation and acetylation [1,2]. In addition, AMPK $\beta$ subunits contain a carbohydrate-binding domain that can interact with oligosaccharide components of glycogen, such that glycogen binding may inhibit AMPK activity [16].

AMPK $\gamma$ subunits contain four cystathionine- $\beta$-synthase (CBS) domains in two tandem repeats, with each tandem repeat referred to as a Bateman domain [1]. Adenine nucleotides bind to the Bateman domains, with three of the four potential binding sites occupied by nucleotides in the crystal structure of the regulatory core of AMPK [17]. Of these three sites, one binds AMP tightly, whereas the two remaining sites bind AMP, ADP or ATP in a competitive manner, thereby regulating AMPK activity. Binding of AMP or ADP promotes phosphorylation of Thr172 on the catalytic $\alpha$ subunit, required for full activation of AMPK (Figure 1), whereas binding of ATP competitively antagonises allosteric activation and stimulation of Thr172 phosphorylation by AMP or ADP [1,2]. The different $\gamma$ subunit isoforms exhibit different adenine nucleotide sensitivity, which may contribute to tissue-specific AMPK regulation [1,2]. As a consequence, increases in the AMP/ATP or ADP/ATP ratio allosterically activate AMPK and further promote activity due to increased Thr172 phosphorylation. However, the binding affinities for AMP, ADP or ATP at any given site are similar, whereas the cellular concentrations of ATP and ADP are considerably higher than AMP, such that it has been argued that the ADP/ATP ratio may be more relevant physiological stimulus for AMPK [reviewed in 1,2]. Furthermore, it has been reasoned that the degree of activation due to allosteric activation by AMP or ADP is modest compared to the effect of phosphorylation at Thr172, such that the effect of allosteric activation may be small in vivo [1]. Therefore the regulation of AMPK by adenine nucleotides warrants further research, particularly to determine the relationship between AMPK activity and the cellular/subcellular concentrations of free ATP, ADP and AMP.

Two AMPK kinases have been identified that mediate phosphorylation of the AMPK $\alpha$ catalytic subunit at Thr172, liver kinase B1 (LKB1) and $\mathrm{Ca}^{2+} /$ calmodulin-dependent protein kinase kinase $\beta($ CaMKK $\beta)$ (Figure 1). Changes in adenine nucleotide concentrations do not directly regulate LKB1 or CaMKK $\beta$, and it has been demonstrated that AMP and ADP binding to the AMPK $\gamma$ subunit inhibits dephosphorylation of Thr172 in the presence of constitutive LKB1 activity (Figure 1) [18]. Increased intracellular $\mathrm{Ca}^{2+}$ concentrations are therefore able to activate AMPK independent of changes in adenine nucleotide ratios in cells expressing CaMKK $\beta$ (Figure 1) $[19,20]$.

In addition to phosphorylation, AMPK $\beta$ subunits are $\mathrm{N}$-terminally myristoylated, and AMPK $\alpha$ subunits are acetylated on lysine residues by p300 acetyltransferase $[1,21]$. Hydrogen peroxide has also been reported to activate AMPK via oxidative modification of $\alpha$ subunit cysteines, yet the physiological relevance of these modifications have yet to be fully characterised $[1,22]$.

\section{Activation and physiological role}

AMPK is activated under conditions in which cellular energy demands are increased or when fuel availability is decreased, due to reduced intracellular ATP and/or increased AMP levels [1,2]. As a consequence, physiological stimuli that activate AMPK include exercise in muscle, ischaemia, glucose deprivation, heat shock and hypoxia $[1,2,23]$. Activated AMPK subsequently phosphorylates key proteins concerned with the regulation 
of carbohydrate and lipid metabolism, resulting in inhibition of ATP-consuming anabolic pathways including fatty acid synthesis, cholesterol and isoprenoid synthesis, hepatic gluconeogenesis and mammalian target of rapamycin (mTOR)-mediated protein translation. Concurrently, AMPK activation stimulates ATP production by increasing fatty acid oxidation, muscle glucose transport, mitochondrial biogenesis and caloric intake $[1,2,23]$. Thus AMPK maintains cellular energy stores and regulates whole body energy balance, leading to the hypothesis that stimulation of AMPK in the metabolic tissues is a useful target for therapies to treat obesity, insulin resistance and type 2 diabetes $[1,2,23]$. In support of this, the widely-used hypoglycaemic biguanide drug, metformin and the thiazolidinedione class of anti-diabetic drugs stimulate AMPK, although it remains uncertain to what extent AMPK activation underlies their clinical action [24-27]. Recently, salicylate has been demonstrated to stimulate AMPK [28]. Furthermore, salicylatestimulated fatty acid oxidation was absent in AMPK $\beta 1^{-/-}$mice, indicating effects of salicylate on lipid metabolism in vivo are mediated by AMPK [28].

Several agents have been used experimentally to activate AMPK. AICAR (5'aminoimidazole-4-carboxamide ribonucleoside) is a nucleoside that has been used widely to activate AMPK in intact cells, tissues and animals. After transport of AICAR into cells, it is phosphorylated to the nucleotide ZMP, which mimics AMP, thereby activating AMPK without altering adenine nucleotide ratios (Figure 1), although a number of AMPKindependent effects of AICAR have been identified [27,29]. In addition to metformin and thiazolidinediones such as rosiglitazone mentioned above, several plant-derived compounds including galgeine, berberine and resveratrol activate AMPK in intact cells by altering adenine nucleotide ratios (Figure 1) [30]. Furthermore, the lipid-lowering statin drugs, and several adipocytokines and hormones including leptin, adiponectin and ghrelin have been demonstrated to activate AMPK in certain tissues, yet the mechanism(s) by which they activate AMPK remain poorly characterised [31-34]. The thienopyridone A769662 is a recently characterised specific activator of AMPK, which stimulates complexes containing the $\beta 1$, but not $\beta 2$ regulatory subunit, in an AMP-independent manner (Figure 1), demonstrating that selective manipulation of AMPK complexes containing specific subunit isoforms is possible $[35,36]$. Intriguingly the mode of action of salicylate is related to that of A769662, which similarly only stimulates AMPK complexes containing the $\beta 1$ non-catalytic subunit and does not alter adenine nucleotide concentrations (Figure 1) [28].

\section{Expression and activation in adipose tissue}

AMPK $\alpha 1$ has been reported to be the principal catalytic subunit isoform expressed in human SCAT and mouse BAT as assessed by AMPK activity in immunoprecipitates using isoform-specific anti-AMPK $\alpha$ subunit antibodies [37,38]. Using similar techniques, AMPK $\alpha 1$ has also been reported to be the dominant isoform in isolated epididymal rat adipocytes and cultured 3T3-L1 adipocytes [39,40]. As these assays assess total cellular/tissue AMPK activity, important roles for AMPK complexes containing the $\alpha 2$ subunit in specific subcellular compartments cannot be excluded, particularly as downregulation of AMPK 22 in cells where it is only a minor isoform can have marked effects [41]. As A769662 and salicylate have been reported to stimulate only AMPK complexes containing the $\beta 1$ subunit isoform, the observations that A769662 activated AMPK in 3T3-L1 adipocytes and salicylate activated AMPK in mouse WAT indicate that adipose tissue and adipocytes express the $\beta 1$ subunit isoform [28,42], observations that are supported by the modest reduction in AMPK Thr172 and ACC phosphorylation reported in the adipose tissue of AMPK $\beta 1^{-1-}$ mice [43]. As the reduction in AMPK phosphorylation was not substantial, this may suggest that WAT expresses significant levels of AMPK $\beta 2$, yet no effect on WAT AMPK activity was observed in AMPK $\beta 2^{-/-}$mice 
[44], indicating that $A M P K \beta 1$ may be the principal $\beta$ isoform in WAT. There is little published information concerning the AMPK subunit isoform expression in the other cell types within WAT or BAT, yet AMPK 1 is reported to be the principal catalytic isoform expressed in human endothelial cells [41] and mouse macrophages [45], which also respond to A769662 or express AMPK $\beta 1[46,47]$.

Several physiological stimuli have been reported to activate adipose AMPK including fasting in mouse and rat WAT [40,48], cold exposure in mouse WAT [38] and exercise in human SCAT and rat epididymal adipose tissue [49,50]. In contrast, androgens have been reported to reduce AMPK activity in mouse WAT [51]. Cold exposure has also been reported to stimulate AMPK in BAT from rats and mice [38,52]. Endogenous stimuli such as $\beta$-adrenergic stimulators, high density lipoproteins, homocysteine and eicosapentaenoic acid have also been reported to stimulate AMPK activity in isolated rodent adipocytes or cultured 3T3-L1 adipocytes [40,53-56], whereas ghrelin and testosterone have been reported to inhibit AMPK activity $[57,58]$. The adipocytokine, adiponectin, secreted by adipose tissue has also been reported to activate adipocyte AMPK [59], illustrating the potential autocrine regulation of adipocyte AMPK activity. Similarly, WAT of mice with an adipose-specific overexpression the leptin receptor exhibited increased AMPK Thr172 phosphorylation, suggesting leptin may activate adipocyte AMPK in an autocrine manner [60]. Finally, metformin has been demonstrated to increase AMPK activity in WAT from mice and volunteers with type 2 diabetes in addition to cultured 3T3-L1 adipocytes $[61,62]$. It is therefore apparent that a number of stimuli may regulate adipose AMPK under physiological and pathophysiological conditions.

\section{EFFECT OF AMPK ON ADIPOCYTE CARBOHYDRATE METABOLISM Glucose transport}

In striated muscle and adipocytes, insulin stimulates glucose uptake, mediated by translocation of vesicles containing GLUT4 to the plasma membrane (Figure 2). The increased influx of glucose provides a substrate for glycogen synthesis in skeletal muscle and TAG synthesis in adipocytes. In skeletal muscle, AMPK activation has been demonstrated to further increase both basal and insulin-stimulated glucose uptake by increasing GLUT4 translocation [63-69]. The effect of AMPK activation on glucose uptake in adipocytes, however, is less clear. In 3T3-L1 adipocytes AICAR increased basal $[39,70]$ and inhibited insulin-stimulated glucose uptake without affecting early steps in the insulin signalling pathway $[39,61]$. On the other hand, in isolated rat adipocytes AICAR inhibited both basal and insulin-stimulated glucose uptake [71,72]. In contrast, AICAR-stimulated glucose uptake was not affected by infection of 3T3-L1 adipocytes with adenoviruses expressing a dominant negative mutant AMPK, despite complete suppression of AMPK activation [70]. Therefore, the involvement of AMPK in the effect of AICAR on basal glucose uptake is uncertain. Despite this, most published evidence supports inhibition of insulin-stimulated glucose uptake by AMPK in adipocytes without affecting early steps in insulin signalling including insulin-stimulated insulin receptor substrate-1 (IRS-1) tyrosine phosphorylation [39,73], phosphatidylinositol 3'kinase (PI3K) recruitment to IRS-1 [39] or PKB activity/phosphorylation [39,61,72,73].

In contrast, treatment of rat adipocytes with globular adiponectin rapidly activated AMPK and increased both basal and insulin-stimulated glucose uptake in a manner sensitive to two different inhibitors of $A M P K$, araA and compound $C$, suggesting involvement of AMPK in the stimulatory effect of adiponectin on glucose uptake [73]. Compound $\mathrm{C}$ has been used widely as an inhibitor of AMPK, yet it inhibits several other protein kinases with similar or greater potency in vitro [74-76]. Similarly AraA, which is metabolised into ara-ATP, a competitive inhibitor for AMPK [77] has also been reported to inhibit adenylyl cyclase, reduce cAMP production and stimulate the mitogenic ERK protein 
kinases [78] Caution should therefore be exercised in interpreting studies that have used compound $\mathrm{C}$ and AraA to implicate a role for AMPK.

In adipocytes, impaired glucose uptake is reflected by a reduction of glycerol 3phosphate production [79], such that inhibition of glucose transport by AMPK is supported by the observation that AICAR impaired the incorporation of glucose into lipids in isolated rat adipocytes $[71,80]$.

\section{AS160}

Insulin-stimulated trafficking of GLUT4 is regulated by two members of the Rab GTPase-activating protein (Rab-GAP) family, TBC1D1 and AS160 (also known as TBC1D4) (Figure 2) [81]. In muscle, PKB phosphorylates AS160, promoting its interaction with 14-3-3 proteins, resulting in inactivation of the Rab-GAP activity and stimulation of GLUT4 trafficking. Similarly, AMPK is reported to phosphorylate TBC1D1, thereby stimulating GLUT4 trafficking in muscle. In adipocytes TBC1D1 does not appear to play a role in GLUT4 trafficking since its expression is very low in 3T3-L1 adipocytes and undetectable in WAT from mice [82]. As AS160 plays an essential role in GLUT4 trafficking in adipocytes [83], it could be reasoned that the differential effects of AMPK activation on insulin-stimulated glucose uptake in adipocytes compared to muscle reflect the expression of TBC1D1 and AS160 in muscle, but AS160 alone in adipocytes (Figure 2). Indeed, in primary rat adipocytes, inhibition of insulin-stimulated glucose uptake by AICAR was accompanied by a reduction in phosphorylation of AS160 at the PKB site Thr651 (equivalent to Thr642 in human), the interaction of AS160 with 14-3-3 and less translocation of GLUT4 to the plasma membrane (Figure 2)[72]. Moreover, this study shows that infection of rat adipocytes with adenoviruses expressing a kinase-dead mutant AMPK $\alpha 1$ completely prevented the effect of AICAR on inhibition of insulin-stimulated AS160 Thr651 phosphorylation and glucose uptake despite only partial inhibition of AICAR-induced AMPK activation [72].

AS160 contains multiple phosphorylation sites and PKB phosphorylates Ser318, Ser588 and Thr642, and to a lesser extent Ser570 and Ser751 of human AS160 in vitro. AMPK on the other hand phosphorylates Ser588 and Ser570 to a similar degree as PKB, yet Thr642 is a poor substrate of AMPK compared to PKB, also reflected in less 14-3-3 binding to AS160 compared to PKB [84]. In 3T3-L1 adipocytes, insulin stimulated phosphorylation of AS160 at Ser318, Ser341, Ser570, Ser588, Thr642, Ser666 and Ser751. However treatment with AMPK activators AICAR, A769662 and phenformin did not phosphorylate AS160 at any of these sites and did not promote 14-3-3 binding [85,86]. This suggests that AMPK does not phosphorylate AS160 at the insulin-regulated sites in adipocytes, yet no studies to date have examined the effect of AMPK activation on sitespecific AS160 phosphorylation other than Thr642 in the presence of insulin.

The mechanism behind this potential inhibition of AS160 phosphorylation by AMPK is therefore uncertain. AS160 Thr642 (Thr651) is phosphorylated by p90 ribosomal S6 kinase (p90RSK) and serum- and glucocorticoid-induced protein kinase (SGK1) in addition to $\mathrm{PKB}$ in vitro [84]. Although $\mathrm{PKB}$ is widely thought to be the kinase responsible for phosphorylation at Thr642 in response to insulin, PKB-stimulated phosphorylation of glycogen synthase kinase-3 were not affected under conditions in which AMPK activation inhibited insulin-stimulated Thr642 phosphorylation [72]. It might be possible that AMPK prevents the specific interaction of PKB with AS160, thereby lowering AS160 phosphorylation. Alternatively, AMPK may activate a phosphatase that dephosphorylates AS160 specifically at Thr651. A third alternative is that AMPK directly phosphorylates AS160 and makes it a poorer substrate for PKB phosphorylation, although this seems unlikely given the lack of effect on many phosphorylation sites as described above. Finally, AMPK might reduce SGK1 or p90RSK-stimulated Thr642 phosphorylation, as both kinases have been reported to be sensitive to insulin $[86,87]$. 


\section{Long term AMPK activation and glucose transport}

Less is known about the long term effects of AMPK activation in adipose tissue. 3T3-L1 adipocytes treated with metformin for 24-48 hours inhibited the fold-stimulation of glucose transport by insulin due to higher basal uptake [61]. Similarly, human SCAT and VAT preadipocyte-derived adipocytes incubated for 24 hours with metformin showed an increase in glucose uptake [88]. Furthermore, human SCAT preadipocyte derived adipocytes exhibited enhanced insulin stimulated glucose uptake after metformin treatment [88]. It has been reported that AMPK activation stimulates GLUT4 expression in muscle [89-92] and 5-day metformin treatment in rainbow trout increased WAT GLUT4 mRNA levels [93], as did prolonged incubation of human SCAT with AICAR ex vivo [94]. In contrast, GLUT4 protein levels were unaffected by prolonged AICAR or metformin treatment of 3T3-L1 adipocytes or in adipose biopsies from volunteers with type 2 diabetes treated with metformin for 10 weeks compared to sulphonylurea treatment [61]. In conclusion the majority of evidence supports inhibition of insulin-stimulated glucose metabolism by AMPK activation in adipocytes but more studies are necessary to fully understand the molecular mechanisms underlying the effect of AMPK.

\section{ROLE OF AMPK IN LIPOLYSIS Regulation of lipolysis}

Lipid droplets in adipocytes are tightly-regulated specialised organelles [95]. In lipolysis, TAG is hydrolysed to glycerol and FAs by the successive action of adipose triglyceride lipase (ATGL; also known as desnutrin) which converts TAG to diacylglycerol (DAG), HSL, which converts DAG into monoacylglycerol (MAG) and MAG lipase, which converts MAG to FAs and glycerol (Figure 3). In the fasted state, noradrenergic stimulation activates PKA which phosphorylates and recruits the lipid droplet scaffolding protein perilipin and HSL to the lipid droplet to stimulate lipolysis [95]. As mentioned previously, insulin, via PKB-mediated phosphorylation and activation of PDE3B, stimulates breakdown of cAMP, thereby suppressing lipolysis.

HSL is phosphorylated by PKA at Ser563 which increases its intrinsic activity and Ser659 and Ser660 which are involved in the translocation of HSL from the cytosol to the lipid droplet (Figure 3) [96]. In the absence of cAMP, perilipin is associated with the protein comparative gene identification-58 (CGI-58). Upon perilipin phosphorylation by PKA, CGI58 is released and interacts with ATGL, stimulating lipase activity [97]. In vitro, PKA has recently been reported to phosphorylate ATGL at various sites including Ser404 (Figure 3) [98], in contrast to an earlier study [99]. Both fasting and exercise increased ATGL phosphorylation at Ser406 (equivalent to human Ser404) in mouse epididymal adipose tissue [98]. Furthermore, expression of an ATGL Ser406Ala mutant in both HEK293 [100] and COS1 cells [98] has been reported to reduce lipolysis, whereas in 293FT cells TAG breakdown was not affected [101]. Reduced forskolin-stimulated lipolysis has also been reported in adipocytes derived from embryonic fibroblasts of $\mathrm{ATGL}^{-/-}$mice infected with retroviruses expressing Ser406Ala mutant ATGL compared to those infected with wild-type ATGL, suggesting that Ser404 phosphorylation is important for increased ATGL activity in adipocytes [98].

\section{AMPK and lipolysis}

Several studies report an anti-lipolytic effect of AMPK $[40,102,103]$, whereas others suggest AMPK stimulates lipolysis [104,105]. Furthermore, exercise has been reported to activate AMPK in rat adipose tissue in a $\beta$-adrenergic receptor-mediated fashion and $\beta$ adrenergic-stimulated lipolysis was sensitive to compound $\mathrm{C}$-sensitive manner, suggesting that AMPK is necessary for adrenaline-induced lipolysis [105]. It is important, however, to note that the FA liberated during lipolysis can directly be re-esterified, thereby consuming 
ATP. As re-esterification of FA is positively correlated with the rate of lipolysis [106-108], an increase in lipolysis may indirectly activate AMPK as a result of an increase in AMP:ATP ratio [109]. This increase in AMPK activity could subsequently inhibit lipolysis, supported by the observation that mice lacking AMPKa1 have smaller adipocytes with higher basal and $\beta$-adrenergic-stimulated lipolysis rates [40]. Importantly, activation of AMPK by AICAR has been reported to initially inhibit lipolysis both in isolated rat adipocytes as well as rats in vivo as reflected by a decrease in serum FAs, yet prolonged AICAR treatment increased lipolysis, which the authors attributed to an increase in ATGL content as well as activity, since HSL activity was lowered [80]. On the other hand, A769662 and salicylate have been reported to reduce fasting plasma FA concentrations in an AMPK $\beta 1$-dependent manner, which may be a result of reduced adipose lipolysis, supporting a role for AMPK in inhibiting lipolysis in vivo. [28].

In adipocytes isolated from human subcutaneous adipose tissue both biguanides and thiazolidinediones inhibited lipolysis in a compound C-sensitive manner, accompanied by activation of AMPK [110]. Furthermore, metformin lowered lipolysis in human subcutaneous adipose tissue from obese subjects in vivo [111]. However, in isolated rat adipocytes metformin has been reported to decrease cellular cAMP levels as well as the activity of PKA suggesting the effect of metformin on lipolysis may be mediated by inhibition of PKA rather than AMPK activation [112].

\section{AMPK regulation of ATGL and HSL?}

Conflicting data have been published concerning the role of AMPK in the regulation of HSL. AMPK has been reported to phosphorylate HSL on Ser565, preventing PKAstimulated activation of HSL (Figure 3) [102,103,113]. Furthermore, ex vivo AMPK activation in human SCAT-derived adipocytes, was demonstrated to reduce HSL translocation to the lipid droplet in association with a compound C-sensitive inhibition of lipolysis [110]. In contrast, mutation of Ser565 to Ala has been reported to prevent the translocation of HSL to the lipid droplet in 3T3-L1 adipocytes, suggesting Ser565 phosphorylation does not inhibit lipolysis and expression of a dominant negative mutant AMPK had no effect on HSL Ser565 phosphorylation under basal or $\beta$-adrenergicstimulated conditions, calling into question AMPK regulation of this site $[114,115]$.

Intriguingly, ATGL Ser404 is an AMPK consensus site and ATGL Ser404 can be phosphorylated by AMPK in vitro [98,100]. In support of this, HEK293 cells and 3T3L1 $\triangle$ CAR adipocytes stimulated with AICAR have been reported to exhibit increased ATGL phosphorylation at Ser406, which was suppressed by compound C [100]. Furthermore, expression of Ser406Ala mutant ATGL completely prevented AICAR-induced lipolysis, whilst injection of mice with AICAR increased serum FA levels, which was not seen in adipose-specific ATGL knockout mice, supporting an ATGL-mediated pro-lipolytic action of AMPK [100]. More recently it was reported that ex vivo AICAR stimulation did not stimulate ATGL Ser404 phosphorylation or lipolysis in subcutaneous adipose tissue from obese subjects [98].

Taken together, these data suggest AMPK may phosphorylate ATGL and HSL to regulate lipolysis (Figure 3), but conclusions are difficult to draw given the lack of studies using tools to manipulate AMPK specifically. Furthermore, the overall effect of AMPK activation on lipolysis is still controversial and the duration and mode of AMPK activation may be of particular importance.

\section{AMPK REGULATION OF LIPOGENESIS}

Early studies in isolated rat adipocytes reported AICAR inhibited lipogenesis and stimulated phosphorylation of ACC, the key regulated step of fatty acid synthesis and fatty acid oxidation (Figure 3) [102]. ACC catalyses the synthesis of malonyl-CoA from acetylCoA and is inhibited by AMPK-mediated phosphorylation at Ser79 on ACC1 or the 
orthologous site Ser212 on ACC2. ACC1 is mainly expressed in lipogenic tissues such as WAT and isolated rat adipocytes infected with adenoviruses expressing constitutively active mutant AMPK showed increased phosphorylation of ACC1 Ser79 whereas infection with dominant negative mutant AMPK inhibited AICAR-stimulated phosphorylation of Ser79, indicating that ACC is certainly regulated by AMPK in adipocytes [40]. This is further supported by the observation that both fasting and exercise stimulate AMPK in rat adipose tissue with a concomitant reduction in malonyl-CoA, which may reflect inhibition of ACC and increased malonyl-CoA decarboxylase activity $[40,50,116,117]$.

Prolonged activation of AMPK by leptin or AICAR in rat adipose tissue $[80,118]$ and metformin in human adipose tissue [61] increased ACC phosphorylation and lowered the expression of lipogenic genes including ACC. In addition, adipocytes from AMPK $\beta 1^{-/}$mice showed increased lipogenesis in adipose explants [43], suggesting a specific role for complexes containing this subunit isoform in attenuating lipogenesis. Lipogenic gene expression is under the control of the sterol regulatory element binding protein $1 \mathrm{c}$ (SREBP-1c) transcription factor. In liver AMPK has been reported to phosphorylate and inactivate SREBP-1c, thereby decreasing the expression of lipogenic genes including ACC1, fatty acid synthase (FAS), and stearoyl-CoA desaturase 1 (SCD1) [119]. There is, however, a dearth of studies examining AMPK regulation of SREBP-1C in adipose tissue. In 3T3-L1 preadipocytes, AICAR inhibited expression of SREBP-1c, yet AICAR treatment for 6 weeks was without effect on SREBP-1c expression in epididymal WAT [120]. Taken together, these data indicate that AMPK activation in adipose tissue is linked to decreased lipid storage by lowering TAG synthesis (Figure 3), but the role of SREBP-1c-regulated lipogenic gene expression in the action of AMPK in adipose tissue is yet to be fully addressed. It is clear that more specific strategies to down- or up-regulate AMPK in adipocytes are required to assess the role of AMPK in both lipogenesis and lipolysis.

\section{AMPK REGULATION OF FATTY ACID OXIDATION}

Malonyl-CoA is not only a precursor for FA synthesis but also regulates FA oxidation by inhibiting carnitine palmitoyltransferase I (CPT1), the rate-limiting enzyme of FA entry into the mitochondrion for subsequent oxidation. As AMPK-mediated phosphorylation and inactivation of ACC reduces malonyl-CoA concentrations, inhibition of CPT1 is relieved and AMPK stimulates FA oxidation in many tissues [1-3]. Despite this, acute stimulation of isolated rat adipocytes with AICAR has been reported to inhibit FA oxidation, suggested to be due to reduced FA uptake [71]. AMPK activation has recently been reported to stimulate translocation of the FA transporter CD36 to the plasma membrane in an AS160-mediated manner in cardiomyocytes [121]. Since CD36 and GLUT4 both undergo similar trafficking routes [122], it is tempting to speculate AMPK activation inhibits CD36 translocation to the plasma membrane in an analogous fashion to GLUT4 in adipocytes, thereby providing a mechanism for reduced FA uptake through AMPK activation (Figure 3). To our knowledge there have been no studies on the effect of AMPK on FA transporters including CD36 in adipocytes.

In contrast to the rapid inhibition of FA oxidation by AICAR [71], sustained activation of AMPK stimulated FA oxidation $[80,123]$ and increased mitochondrial content in adipocytes [118,124]. In support of this, sustained AICAR stimulation increased WAT expression of peroxisome proliferator-activated receptor (PPAR) $\alpha$, PPAR $\delta$ and PPAR $\gamma$ coactivator-1 $\alpha$ (PGC-1 $\alpha$ ), all of which influence the expression of enzymes involved in FA oxidation and mitochondrial biogenesis $[80,100]$. These structural changes in adipocytes after prolonged AICAR administration were accompanied by a reduction in body fat mass. However it is important to note that whole body energy expenditure was increased after sustained treatment with AICAR as AMPK activation also increases the oxidative capacity of liver and muscle $[125,126]$. As with lipolysis, the role of AMPK in the regulation of WAT FA oxidation may therefore be dependent on the duration and mode of AMPK stimulation, 
whereby AMPK activation rapidly inhibits FA oxidation, potentially due to effects on FA transport, yet prolonged AMPK activation stimulates FA oxidation.

\section{AMPK AND ADIPOGENESIS}

Differentiation of preadipocytes involves a highly regulated transcriptional cascade induced by hormones including insulin and glucocorticoids and is characterised by expression of FAS and adipocyte-specific fatty acid binding protein (aP2) in addition to increased expression of the PPAR and CCAAT/enhancer binding protein (C/EBP) transcription factors [127]. The process begins with re-entry of growth-arrested preadipocytes into the cell cycle where they undergo several rounds of mitosis. This initial phase is known as mitotic clonal expansion (MCE) and is accompanied by the transient expression of $\mathrm{C} / \mathrm{EBP} \beta$ and $\mathrm{C} / \mathrm{EBP} \delta$. These transcription factors subsequently stimulate transcription of PPAR $\gamma$, which in turn can activate C/EBP $\alpha$. PPAR $\gamma$ and C/EBP $\alpha$ exist in a positive feedback loop to propagate differentiation and induction of late adipogenic genes including aP2 and Fas in the terminal differentiation phase [128].

Proliferation and adipogenesis are anabolic processes which multiple lines of evidence suggest are inhibited by AMPK. Activation of AMPK has been proposed to suppress proliferation in a variety of cell types in different ways. Most recently, studies in cell lines using AICAR or metformin have proposed AMPK inhibits proliferation via inhibition of mTOR $[1,129]$. Stimulation with AICAR, A769662 and infection with viruses expressing a constitutively active mutant AMPK have been reported to inhibit endothelial cell proliferation via elevation of p21 and p27 expression [130] and AICAR has been demonstrated to block growth of the HepG2 cell line via phosphorylation of p53, all leading to cell cycle arrest [131]. The exact mechanism by which AMPK inhibits proliferation remains to be fully elucidated, particularly in preadipocytes of WAT, and may differ depending on the type of cell.

AMPK activation has been suggested to inhibit adipogenesis via the MCE phase, with reduced expression of C/EBP $\beta$ (which is essential for initiation of the adipogenic transcriptional cascade), and subsequent inhibition of PPAR $\gamma, \mathrm{C} / \mathrm{EBP} \alpha$ and late adipogenic markers such as FAS, aP2 and SREBP-1c [132]. It has been demonstrated in 3T3-L1 preadipocytes that $\mathrm{A} 769662$ inhibited accumulation of lipid droplets and reduced expression of $\mathrm{C} / \mathrm{EBP} \alpha$ and PPAR $\gamma$ as well as earlier adipogenic transcription factors $\mathrm{C} / \mathrm{EBP} \beta$ and $\mathrm{C} / \mathrm{EBP} \delta$ [42]. Interestingly, $\mathrm{A} 769662$ was shown to maintain $\mathrm{C} / \mathrm{EBP} \delta$ expression, where it would normally decline [42]. AICAR treatment blocked adipogenesis at the MCE phase and reduced expression of C/EBP $\alpha$, PPAR $\gamma$ SREBP-1c and aP2 [120,132]. Recently, novel synthetic compounds which are structurally similar to resveratrol have been identified which have been proposed to activate AMPK indirectly [133]. As with other established AMPK activators, they have been found to inhibit differentiation during the MCE phase and reduce expression of several adipogenic markers, including PPAR $\gamma, \mathrm{C} / \mathrm{EBP} \alpha, \mathrm{FAS}$ and aP2 [133].

While these studies all indicate AMPK acts at the early proliferation phase to inhibit adipogenesis, the exact mechanism by which AMPK produces these effects is still unclear. It has recently been suggested that AICAR may inhibit adipocyte differentiation via modulation of the WNT/ $\beta$-catenin pathway [134]. In that study, AICAR stimulation during adipogenesis of 3T3-L1 adipocytes led to an increase in $\beta$-catenin expression and nuclear accumulation concomitant with the significant reduction in expression of adipogenic genes; this was ablated with siRNA-mediated knockdown of $\beta$-catenin, providing a possible mechanism by which AMPK inhibits adipogenesis [134]. Furthermore, AMPK activation has been proposed to maintain expression of preadipocyte factor-1 (Pref-1) which inhibits adipogenesis [135]. 
An increase in adipose tissue mass can either be due to an increase in adipocyte size (hypertrophy), an increase in adipocyte number (hyperplasia), or both. Studies using mice in which catalytic subunit isoforms of AMPK have been knocked out have been used to examine the role of AMPK in changes in adipose tissue mass. AMPK $\alpha 2$ deficient mice fed a high fat diet exhibited increased adipose tissue mass compared to wild type littermates, resulting from adipocyte hypertrophy, with no change in cell number or adipogenic marker expression [136]. Similar observations were made in a recent study which demonstrated AMPKa1-deficient mice fed a high fat diet also showed increased adiposity compared with their wild type littermates, and that this was the result of adipocyte hypertrophy [137]. Caution has to be taken when interpreting these data as this may reflect ablation of AMPK-mediated increased fatty acid oxidation and a concomitant decrease in lipogenesis. Also the animal models utilised in these studies have a global knockout of either AMPK $\alpha$ isoform, such that observed effects may not be a direct effect of reduced AMPK activity in adipose or adipocytes. There is a need for adipose-specific knockouts of AMPK isoforms to help address this.

\section{REGULATION OF ADIPOSE ADIPOCYTOKINES AND INFLAMMATION BY AMPK}

As mentioned previously, WAT has an endocrine function in addition to its key role in metabolism, secreting a large number of adipocytokines, which influence systemic and local metabolism in addition to inflammatory pathways. Dysfunctional metabolism and a chronic sub-clinical proinflammatory environment are observed in the WAT of obese individuals, and this proinflammatory environment contributes to the development of systemic insulin resistance and type 2 diabetes [5].

\section{Adipocytokines}

Proteins secreted by WAT that influence metabolism and inflammation include leptin, adiponectin, monocyte chemoattractant protein-1 (MCP-1), tumour necrosis factor- $\alpha$ (TNF- $\alpha$ ), interleukin (IL)-1 $\beta$ and IL-6. Plasma leptin levels are positively correlated with an increase in total body fat mass as a result of more leptin being released from large, hypertrophic adipocytes compared with smaller adipocytes [138]. Leptin acts at neurones within the hypothalamus to regulate satiety, but also exerts antidiabetic actions independent of its effect on body mass [139]. Adiponectin is a protein secreted exclusively from adipose tissue [140], with plasma levels correlating negatively with obesity [141]. Adiponectin acts to improve peripheral insulin sensitivity and has systemic antiinflammatory effects [142]. MCP-1, TNF- $\alpha$, IL-1 $\beta$ and IL-6 are proinflammatory chemokines or cytokines secreted by WAT, and are increased in concentration upon obesity [143].

\section{Proinflammatory adipocytokines and obesity}

Obesity is associated with the low-grade inflammation of WAT and increased necrosis/apoptosis of adipocytes [144]. Proinflammatory cytokines signal via distinct pathways, with TNF- $\alpha$ and IL-1 $\beta$ signalling via the proinflammatory transcription factor nuclear factor $\kappa B(N F \kappa B)$ and MAP kinases, whereas IL-6 signals via a JAK/STAT pathway [4]. These pathways culminate in the secretion of chemokines including MCP-1, recruiting macrophages to the site of inflammation [145,146]. Studies in genetically obese $(o b / o b)$ and high fat diet-induced obese mice have suggested the presence of other chemokine receptors and ligands, including macrophage inflammatory protein-1 (MIP-1), RANTES (regulated and normal $T$ cell expressed and secreted) and MCP-2 are also upregulated in obesity [147], demonstrating the complexity of the proinflammatory profile of obese adipose tissue. Migration of macrophages into adipose tissue is also stimulated by necrotic adipocytes [144], nutrient excess (increased FA) (Figure 4) [148], or a combination of these. Interplay between the different cell types within adipose tissue, 
particularly between adipocytes and macrophages, is central to the development of inflammation within the tissue. Several genetic studies have demonstrated the importance of macrophages in the development of obesity-related inflammation and insulin resistance [149-152]. Macrophages have been reported to aggregate and form crown-like structures surrounding necrotic adipocytes (Figure 4) [143,153,154]. Macrophages can also be recruited and rendered proinflammatory by the presence of saturated FAs (as is often the case in obesity) which activate the Toll-like receptor (TLR) family [155]. Indeed, mice with hematopoietic deletion of TLR are largely protected from obesity-induced inflammation and insulin resistance [156]. Following migration into adipose tissue in response to one or more of the factors detailed above, macrophages then undergo a shift in their polarity, switching from an anti-inflammatory, 'alternatively activated' M2 state to a 'classically activated', proinflammatory M1 state (Figure 4) [5]. Conversely, adiponectin has been reported to switch adipose macrophages into the anti-inflammatory M2 state [142]. Macrophages can also induce inflammatory responses via activation of the inflammasome, the best characterised of which is the nucleotide-binding and oligomerisation domain-like receptor family pyrin domain-containing 3 (NLRP3) inflammasome. Activation of the NLRP3 inflammasome leads to maturation and secretion of proinflammatory cytokines IL-1 $\beta$ and IL-18, and as a result has been linked to obesity-associated inflammation and development of insulin resistance and type 2 diabetes [157].

\section{AMPK inhibits inflammation in adipose tissue}

There have been a number of studies suggesting AMPK is anti-inflammatory in different tissues and cell types including those that constitute adipose such as adipocytes, endothelial cells and macrophages [4]. Various studies have reported that activation of AMPK can inhibit synthesis of proinflammatory cytokines such as TNF- $\alpha$, IL-1 $\beta$ and IL- 6 in macrophages [45,47,158,159] and IL-6 and IL-8 in adipocytes [94]. Conversely, AMPK activation has been reported to upregulate expression of anti-inflammatory cytokine IL-10 in macrophages $[47,159]$. In human SCAT cultured ex vivo, AICAR was reported to reduce TNF- $\alpha$ and IL-6 secretion (Figure 4) [37]. Berberine, which activates AMPK and inhibits proinflammatory signalling in isolated macrophages also been reported to inhibit cytokine expression in adipose tissue of obese $\mathrm{db} / \mathrm{db}$ mice, yet the AMPK-dependence of this has not been demonstrated [158]. A very recent study has shown that activation of the NLRP3 inflammasome is markedly increased in myeloid cells from patients with type 2 diabetes, and found that treatment with metformin appeared to reduce maturation and secretion of $\mathrm{IL}-1 \beta$ and IL-18 in monocyte-derived macrophages. This was suggested to occur in an AMPK-dependent manner; however the mechanism remains to be elucidated [160].

Recent studies have utilised AMPK-deficient mice to confirm the anti-inflammatory role of AMPK. It has been reported that high fat diet-fed AMPK $\alpha 1^{-1-}$ mice had an increased level of infiltration of proinflammatory macrophages and exhibited an elevation in IL-6, IL$1 \beta$ and TNF- $\alpha$ at the mRNA level in adipose tissue, as well as significantly higher levels of circulating cytokines [137]. Furthermore, increased production of IL-1 $\beta$ and TNF- $\alpha$ (but not IL-6) were observed in AMPK 1 1-deficient macrophages stimulated with TLR4 activator lipopolysaccharide, and these macrophages displayed increased activity of proinflammatory signalling pathways compared with wild type macrophages [137]. Stable knockdown of AMPK 1 in 3T3-L1 adipocytes supported these findings, with higher mRNA levels of proinflammatory cytokines TNF- $\alpha$ and IL-1 $\beta$ as well as MCP-1 in response to FA treatment than control 3T3-L1 cells [137]. Similarly, a study utilising obese AMPK $\beta 1^{-/-}$mice reported that AMPK activation is crucial for the regulation of macrophage polarisation, as bone marrow-derived macrophages from mice lacking the $\beta 1$ subunit had reduced levels of AMPK activation and elevated c-Jun N-terminal kinase (JNK) phosphorylation in 
response to proinflammatory stimuli [47]. Interestingly, however, the ability of AMPK to suppress palmitate-stimulated JNK phosphorylation appears to be blocked by inhibition of fatty acid oxidation [47].

It has been shown that activation of AMPK drives anti-inflammatory polarisation macrophages to M2, (Figure 4) while inhibition of AMPKa expression by RNA interference or transfection with a dominant negative form of AMPK significantly enhanced mRNA and protein expression of TNF- $\alpha$ and IL-6 [159]. Furthermore, PPARy-coactivator-1 $\beta$ (PGC1 $\beta$ ) and oxidative metabolism has been reported to be important in priming macrophages for alternative activation and attenuates proinflammatory signalling, suggesting resident M2 macrophages are reliant upon FA metabolism and AMPK activity to maintain the antiinflammatory phenotype [159,161]. Conversely, macrophages from AMPK $\beta 1^{-/}$mice were found to have reduced mitochondrial content consistent with their M1 activation and reduced rates of fatty acid oxidation [47]. There is evidence to suggest that mature adipocytes may modulate macrophage polarisation via secretion of lipid mediators which activate AMPK in macrophages and impair their polarisation to a pro-inflammatory phenotype [162].

\section{Adipocytokines Regulated by AMPK}

As previously described, AMPK activation has been reported to suppress inflammatory responses in obese adipose tissue [37,94,158,163]. Adiponectin and leptin levels may also be regulated by AMPK as high fat diet-fed AMPK $\beta 1^{-/-}$mice displayed significantly less adiponectin and increased leptin concentrations relative to chow-fed or wild type littermates [47]. Also, AICAR increased adiponectin gene expression in human SCAT cultured ex vivo [37]. These data suggest that AMPK activation is partially able to override obesity-induced dysregulation of adiponectin and leptin concentrations. However, AICAR and metformin have also been reported to suppress adiponectin expression in 3T3L1 adipocytes [164].

\section{AMPK regulation by adipocytokines}

Adipocytes express adiponectin receptors, indicating that adiponectin can act in an autocrine fashion [165]. Adiponectin stimulates AMPK activity in several tissues by a mechanism that has yet to be fully characterised, but adiponectin also engages many other signalling pathways and has AMPK-independent effects [142]. A few studies have suggested that AMPK itself can be regulated by proinflammatory cytokines in different cell types, for example TNF- $\alpha$ has been reported to activate AMPK in various cell lines including endothelial and kidney cell lines [166]. Conversely, it has been reported to suppress AMPK activity in myotubes and muscle [167]. IL-6 has similarly been reported to influence AMPK activity in different cell types are also varied, with evidence suggesting IL6 stimulates AMPK in muscle, with suppressed AMPK activity being reported in IL-6deficient mice [168,169], yet in endothelial cells IL-6 has been proposed to inhibit AMPK activity [170]. In a recent study IL-6 was found to increase phosphorylation of ACC and AMPK in cultured epididymal adipose tissue (eWAT) and was independent of any increase in lipolysis [171]. It is therefore apparent that certain adipocytokines may regulate AMPK activity, however this is appears to be cell type-specific and further investigation is required, particularly to elucidate the effect of adipocytokines on AMPK in adipose tissue.

\section{AMPK AND BROWN ADIPOSE}

As mentioned previously, brown adipocytes contain high numbers of mitochondria and characteristically express UCP1, which allows thermogenesis, yet the exact role of BAT in human energy balance remains uncertain [6,7]. Cold exposure has been reported to stimulate AMPK in BAT from rats and mice $[38,52]$ and both AICAR and $\beta 3$-adrenergic 
stimulation increase AMPK activity and glucose transport in cultured mouse brown adipocytes in an AraA-sensitive manner [172,173]. These findings have been extended in mice, indicating that adrenergic nerves stimulate AMPK in BAT in vivo [174]. Furthermore, AMPK activity increases during brown adipocyte differentiation, and siRNA targeted to AMPK inhibited differentiation into mature brown adipocytes, suggesting AMPK promotes differentiation into thermogenic BAT [175]. Indeed, prolonged treatment of mice with AICAR increased the extent of BAT within WAT deposits in mice [175]. These studies suggest that AMPK may play a role in differentiation into FA oxidising BAT, leading to greater energy expenditure, yet AMPK $\alpha 1^{-/-}$mice showed no alteration in cold tolerance or acute nonshivering thermogenesis, although a compensatory increase in AMPK $\alpha 2$ expression may explain this lack of effect [176].

\section{REGULATION OF AMPK IN HUMAN ADIPOSE}

In adipocytes isolated from the SCAT of normal to moderately overweight women, the thiazolidinedione and biguanide antidiabetic drugs have been demonstrated to activate AMPK and inhibit lipolysis in a compound C-sensitive manner ex vivo [110]. Similarly, cultured SCAT explants from similar individuals stimulated with AICAR exhibited increased adiponectin and GLUT4 expression and reduced TNF- $\alpha$, IL-8 and IL-6 secretion [37,94]. Few studies have examined human adipose AMPK activity in vivo, however. Of these, exercise has been reported to activate AMPK in SCAT from healthy individuals [49], yet this may depend on the degree of exercise, as a further study has indicated that SCAT AMPK activity is unaffected [177]. AMPK expression and activity has been reported to be lower in VAT compared to SCAT of morbidly obese individuals $[178,179]$. Furthermore, when this morbidly obese group was divided into insulin resistant and insulin sensitive subgroups, AMPK activity was reduced in the adipose tissue of the insulin resistant obese volunteers compared to BMI-matched controls, suggesting an association in WAT between AMPK activity and insulin sensitivity $[179,180]$. Intriguingly, AMPK activity is also reported to be decreased in VAT from individuals with Cushing's syndrome, which is also associated with insulin resistance [181]. Finally, metformin was recently shown to increase SCAT AMPK activity of individuals with type 2 diabetes in a randomised glycaemiacontrolled crossover study [61]. Although these clinical studies have been on small numbers of people, these data do suggest that improving AMPK activity in adipose tissue in people with insulin resistance may benefit adipose function and that exercise and metformin may be able to achieve this. It has yet to be proven whether the activation of AMPK observed with exercise, metformin or in more insulin-sensitive individuals represents increased AMPK activity in adipocytes or the other constituent cells of adipose, however.

\section{CONCLUSIONS}

The studies of AMPK function in adipose published to date are largely based on isolated rodent adipocytes or cells that have been differentiated into adipocytes in vitro. As these cells are intractable to molecular biology techniques that would allow specific up- or downregulation of AMPK, most studies have relied on less specific methods of transiently activating or inhibiting AMPK. Similarly, data obtained in animals where one isoform of AMPK has been genetically deleted have revealed interesting potential actions of AMPK in adipose tissue, but these may represent secondary indirect effects mediated by downregulation of AMPK in other tissues, particularly liver and muscle. There is, therefore, an urgent need for animals in which AMPK is specifically ablated in adipocytes to confirm the actions of AMPK in adipose. The heterogeneity of adipose tissue in terms of constituent cell types and different depots increase the challenge of determining the function of AMPK in adipose tissue. The exciting new observations concerning the role of BAT in man is another area in which the role of AMPK should be explored. The few 
investigations of AMPK activity in human adipose have demonstrated that AMPK activation in adipose tissue is feasible in man and that this may have beneficial consequences attenuating adipose dysfunction and inflammation. As activators, such as A769662 and salicylate, that target specific subunit isoforms of AMPK are already used in the laboratory, it is feasible to design activators of AMPK are targeted to certain tissues, given the differential tissue distribution of AMPK subunit isoforms. It is clear, therefore, that AMPK regulates carbohydrate and lipid metabolism in adipose tissue and suppresses proinflammatory signalling that contributes to adipose tissue dysfunction and insulin resistance. More studies that specifically manipulate AMPK activity in the constituent cells of adipose tissue are required to further characterise its role.

\section{FUNDING}

Our own work was supported by project grants and Ph.D. studentships from Diabetes UK and project grants from the British Heart Foundation. 


\section{REFERENCES}

1 Carling, D., Thornton, C., Woods, A. and Sanders, M.J. (2012) AMP-activated protein kinase: new regulation, new roles? Biochem. J. 445, 11-27

2 Hardie, D.G., Ross, F.A. and Hawley, S.A. (2012) AMPK: a nutrient and energy sensor that maintains energy homeostasis. Nat. Rev. Mol. Cell. Biol. 13, 251-262

3 Viollet, B. and Andreelli, F. (2011) AMP-activated protein kinase and metabolic control. Handb. Exp. Pharmacol. 203, 303-330

4 Salt, I.P. and Palmer, T.M. (2012) Exploiting the anti-inflammatory effects of AMPactivated protein kinase activation. Expert Opin. Investig. Drugs 21, 1155-1167

5 Glass, C.K. and Olefsky, J.M. (2012) Inflammation and lipid signaling in the etiology of insulin resistance. Cell Metab. 15, 635-645

6 Marzolla, V., Armani, A., Zennaro, M.C., Cinti, F., Mammi, C., Fabbri, A., Rosano, G.M. and Caprio, M. (2012) The role of the mineralocorticoid receptor in adipocyte biology and fat metabolism. Mol. Cell. Endocrinol. 350, 281-288

7 Tam, C.S., Lecoultre, V. and Ravussin, E. (2012) Brown adipose tissue: mechanisms and potential therapeutic targets. Circulation 125, 2782-2791

8 Daval, M., Foufelle, F. And Ferre, P. (2006) Functions of AMP-activated protein kinase in adipose tissue. J. Physiol. 574, 55-62

9 Berggreen, C., Gormand, A., Omar, B., Degerman, E. and Göransson, O. (2009) Protein kinase B activity is required for the effects of insulin on lipid metabolism in adipocytes. Am. J. Physiol. Endocrinol. Metab. 296, E635-E646

10 Fox, C.S., Massaro, J.M., Hoffmann, U., Pou, K.M., Maurovich-Horvat, P., Liu, C.Y., Vasan, R.S., Murabito, J.M., Meigs, J.B., Cupples, L.A., D'Agostino, R.B.Sr. and O'Donnell, C.J. (2007) Abdominal visceral and subcutaneous adipose tissue compartments: association with metabolic risk factors in the Framingham Heart Study. Circulation 116, 39-48

11 Eringa, E.C., Bakker, W. and van Hinsbergh, V.W. (2012) Paracrine regulation of vascular tone, inflammation and insulin sensitivity by perivascular adipose tissue. Vascul .Pharmacol. 56, 204-209

12 Carling, D., Zammit, V.A. and Hardie, D.G. (1987) A common bicyclic protein kinase cascade inactivates the regulatory enzymes of fatty acid and cholesterol biosynthesis. FEBS Lett. 223, 217-222

13 Cheung, P. C., Salt, I. P., Davies, S. P., Hardie, D. G. and Carling, D. (2000) Characterization of AMP-activated protein kinase y subunit isoforms and their role in AMP binding. Biochem. J. 346, 659-669

14 Salt, I. P., Celler, J. W., Hawley, S. A., Prescott, A., Woods, A., Carling, D. and Hardie, D. G. (1998) AMP-activated protein kinase: greater AMP dependence, and preferential nuclear localization, of complexes containing the $\alpha 2$ isoform. Biochem. J. 334, 177-187

15 Xiao, B., Sanders, M.J., Underwood, E., Heath, R., Mayer, F., Carmena, D. J., Jing, C., Walker, P.A., Eccleston, J.E. and Haire, L.F. (2011) Structure of mammalian AMPK and its regulation by ADP. Nature 472, 230-233

16 McBride, A., Ghilagaber, S., Nikolaev, A. and Hardie, D.G. (2009) The glycogenbinding domain on the AMPK beta subunit allows the kinase to act as a glycogen sensor. Cell Metab. 9, 23-34

17 Xiao, B., Heath, R., Saiu, P., Leiper, F.C., Leone, P., Jing, C., Walker, P.A., Haire, L., Eccleston, J.F., Davis, C.T., Martin, S.R., Carling, D. and Gamblin, S.J. (2007) Structural basis for AMP binding to mammalian AMP-activated protein kinase. Nature 449, 496-500

18 Sakamoto, K., Göransson, O., Hardie, D.G. and Alessi, D.R. (2004) Activity of LKB1 and AMPK-related kinases in skeletal muscle: effects of contraction, phenformin, and AICAR. Am. J. Physiol. Endocrinol. Metab. 287, E310-E317 
19 Hawley, S. A., Pan, D. A., Mustard, K. J., Ross, L., Bain, J., Edelman, A. M., Frenguelli, B. G. and Hardie, D. G. (2005) Calmodulin-dependent protein kinase kinase $\beta$ is an alternative upstream kinase for AMP-activated protein kinase. Cell Metab. 2, 9-19

20 Woods, A., Dickerson, K., Heath, R., Hong, S. P., Momcilovic, M., Johnstone, S. R., Carlson, M. and Carling, D. (2005) $\mathrm{Ca}^{2+} /$ calmodulin-dependent protein kinase kinase $\beta$ acts upstream of AMP-activated protein kinase in mammalian cells. Cell Metab. 2, 21-33

21 Lin, Y. Y., Kiihl, S., Suhail, Y., Liu, S. Y., Chou, Y. H., Kuang, Z., Lu, J. Y., Khor, C. N., Lin, C. L. and Bader, J. S. (2012) Functional dissection of lysine deacetylases reveals that HDAC1 and p300 regulate AMPK. Nature 482, 251-255

22 Zmijewski, J.W., Banerjee, S., Bae, H., Friggeri, A., Lazarowski, E.R. and Abraham, E. (2010) Exposure to hydrogen peroxide induces oxidation and activation of AMPactivated protein kinase. J. Biol. Chem. 285, 33154-33164.

23 Zhang, B. B., Zhou, G. and Li, C. (2009) AMPK: an emerging drug target for diabetes and the metabolic syndrome. Cell Metab. 9, 407-416

24 Fryer, L.G., Parbu-Patel, A. and Carling, D. (2002) The Anti-diabetic drugs rosiglitazone and metformin stimulate AMP-activated protein kinase through distinct signaling pathways. J. Biol. Chem. 277, 25226-25232

25 Boyle, J.G., Salt, I.P. and McKay, G.A. (2010) Metformin action on AMP-activated protein kinase: a translational research approach to understanding a potential new therapeutic target. Diabet. Med. 27, 1097-1106

26 Foretz, M., Hebrard, S., Leclerc, J., Zarrinpashneh, E., Soty, M., Mithieux, G., Sakamoto, K., Andreelli, F. and Viollet, B. (2010) Metformin inhibits hepatic gluconeogenesis in mice independently of the LKB1/AMPK pathway via a decrease in hepatic energy state. J. Clin. Invest. 120, 2355-2369

27 Guigas, B., Bertrand, L., Taleux, N., Foretz, M., Wiernsperger, N., Vertommen, D., Andreelli, F., Viollet, B. and Hue, L. (2006) 5-Aminoimidazole-4-carboxamide-1-betaD-ribofuranoside and metformin inhibit hepatic glucose phosphorylation by an AMPactivated protein kinase-independent effect on glucokinase translocation. Diabetes 55, 865-874

28 Hawley, S.A., Fullerton, M.D., Ross, F.A., Schertzer, J.D., Chevtzoff, C., Walker, K.J., Peggie, M.W., Zibrova, D., Green, K.A., Mustard, K.J., Kemp, B.E., Sakamoto, K., Steinberg, G.R. and Hardie, D.G. (2012) The ancient drug salicylate directly activates AMP-activated protein kinase.Science 336, 918-922

29 López, J.M., Santidrián, A.F., Campàs, C. and Gil, J. (2003) 5-Aminoimidazole-4carboxamide riboside induces apoptosis in Jurkat cells, but the AMP-activated protein kinase is not involved. Biochem. J. 370, 1027-1032

30 Hawley, S. A., Ross, F. A., Chevtzoff, C., Green, K. A., Evans, A., Fogarty, S., Towler, M. C., Brown, L. J., Ogunbayo, O. A., Evans, A. M. and Hardie, D. G. (2010) Use of cells expressing y subunit variants to identify diverse mechanisms of AMPK activation. Cell Metab. 11, 554-565

31 Sun, W., Lee, T.S., Zhu, M., Gu, C., Wang, Y., Zhu, Y. and Shyy, J.Y. (2006) Statins activate AMP-activated protein kinase in vitro and in vivo. Circulation 114, 2655-2662

32 Kou, R., Sartoretto, J. and Michel, T. (2009) Regulation of Rac1 by simvastatin in endothelial cells: differential roles of AMP-activated protein kinase and calmodulindependent kinase kinase-beta. J. Biol. Chem. 284, 14734-14743

33 Minokoshi, Y., Kim, Y.B., Peroni, O.D., Fryer, L.G., Müller, C., Carling, D. and Kahn, B.B. (2002) Leptin stimulates fatty-acid oxidation by activating AMP-activated protein kinase. Nature 415, 339-343

34 Yamauchi, T., Kamon, J., Minokoshi, Y., Ito, Y., Waki, H., Uchida, S., Yamashita, S., Noda, M., Kita, S., Ueki, K., Eto, K., Akanuma, Y., Froguel, P., Foufelle, F., Ferre, P., 
Carling, D., Kimura, S., Nagai, R., Kahn, B.B. and Kadowaki, T. (2002) Adiponectin stimulates glucose utilization and fatty-acid oxidation by activating AMP-activated protein kinase. Nat. Med. 8, 1288-1295

35 Cool, B., Zinker, B., Chiou, W., Kifle, L., Cao, N., Perham, M., Dickinson, R., Adler, A., Gagne, G. and lyengar, R. (2006) Identification and characterization of a small molecule AMPK activator that treats key components of type 2 diabetes and the metabolic syndrome. Cell Metab. 3, 403-416

36 Scott, J.W., van Denderen, B.J., Jorgensen, S.B., Honeyman, J.E., Steinberg, G.R., Oakhill, J.S., Iseli, T.J., Koay, A., Gooley, P.R., Stapleton, D. and Kemp, B.E. (2008) Thienopyridone drugs are selective activators of AMP-activated protein kinase beta1containing complexes. Chem. Biol. 15, 1220-1230

37 Lihn, A.S., Jessen, N., Pedersen, S.B., Lund, S. and Richelsen, B. (2004) AICAR stimulates adiponectin and inhibits cytokines in adipose tissue. Biochem. Biophys. Res. Commun. 316, 853-858

38 Mulligan, J.D., Gonzalez, A.A., Stewart, A.M., Carey, H.V. and Saupe, K.W. (2007) Upregulation of AMPK during cold exposure occurs via distinct mechanisms in brown and white adipose tissue of the mouse. J. Physiol. 580, 677-684.

39 Salt, I.P., Connell, J.M. and Gould, G.W. (2000) 5-aminoimidazole-4-carboxamide ribonucleoside (AICAR) inhibits insulin-stimulated glucose transport in 3T3-L1 adipocytes. Diabetes 49, 1649-1656

40 Daval, M., Diot-Dupuy, F., Bazin, R., Hainault, I., Viollet, B., Vaulont, S., Hajduch, E., Ferré, .P and Foufelle, F. (2005) Anti-lipolytic action of AMP-activated protein kinase in rodent adipocytes. J. Biol. Chem. 280, 25250-25257

41 Wang, S., Zhang, M., Liang, B., Xu, J., Xie, Z., Liu, C., Viollet, B., Yan, D. and Zou, M.H. (2010) AMPKalpha2 deletion causes aberrant expression and activation of $\mathrm{NAD}(\mathrm{P}) \mathrm{H}$ oxidase and consequent endothelial dysfunction in vivo: role of $26 \mathrm{~S}$ proteasomes. Circ. Res. 106, 1117-1128

42 Zhou, Y., Wang, D., Zhu, Q., Gao, X., Yang, S., Xu, A. and Wu, D. (2009) Inhibitory effects of A-769662, a novel activator of AMP-activated protein kinase, on 3T3-L1 adipogenesis. Biol. Pharm. Bull. 32, 993-998

43 Dzamko, N., van Denderen, B.J., Hevener, A.L., Jørgensen, S.B., Honeyman, J., Galic, S., Chen, Z.P., Watt, M.J., Campbell, D.J., Steinberg, G.R. and Kemp, B.E. (2010) AMPK beta1 deletion reduces appetite, preventing obesity and hepatic insulin resistance. J. Biol. Chem. 285, 115-22

44 Steinberg, G.R., O'Neill, H.M., Dzamko, N.L., Galic, S., Naim, T., Koopman, R., Jørgensen, S.B., Honeyman, J., Hewitt, K., Chen, Z.P., Schertzer, J.D., Scott, J.W., Koentgen, F., Lynch, G.S., Watt, M.J., van Denderen, B.J., Campbell, D.J. and Kemp, B.E. (2010) Whole body deletion of AMP-activated protein kinase $\beta 2$ reduces muscle AMPK activity and exercise capacity. J. Biol. Chem 285, 37198-37209

45 Yang, Z., Kahn, B.B., Shi, H. and Xue, B.Z. (2010) Macrophage alpha1 AMPactivated protein kinase (alpha1AMPK) antagonizes fatty acid-induced inflammation through SIRT1. J. Biol. Chem. 285, 19051-19059

46 Reihill, J.A., Ewart, M.A. and Salt, I.P. (2011) The role of AMP-activated protein kinase in the functional effects of vascular endothelial growth factor-A and -B in human aortic endothelial cells. Vasc. Cell 3, 9

47 Galic, S., Fullerton, M.D., Schertzer, J.D., Sikkema, S., Marcinko, K., Walkley, C.R., Izon, D., Honeyman, J., Chen, Z.P., van Denderen, B.J., Kemp, B.E. and Steinberg, G.R. (2011) Hematopoietic AMPK $\beta 1$ reduces mouse adipose tissue macrophage inflammation and insulin resistance in obesity. J. Clin. Invest. 121, 4903-4915

48 Sponarova, J., Mustard, K.J., Horakova, O., Flachs, P., Rossmeisl, M., Brauner, P., Bardova, K., Thomason-Hughes, M., Braunerova, R., Janovska, P., Hardie, D.G. and 
Kopecky, J. (2005) Involvement of AMP-activated protein kinase in fat depot-specific metabolic changes during starvation. FEBS Lett. 579, 6105-6110

49 Watt, M.J., Holmes, A.G., Pinnamaneni, S.K., Garnham, A.P., Steinberg, G.R., Kemp, B.E. and Febbraio, M.A. (2006) Regulation of HSL serine phosphorylation in skeletal muscle and adipose tissue. Am. J. Physiol. Endocrinol. Metab. 290, E500E508

50 Park, H., Kaushik, V.K., Constant, S., Prentki, M., Przybytkowski, E., Ruderman, N.B. and Saha, A.K. (2002) Coordinate regulation of malonyl-CoA decarboxylase, snglycerol-3-phosphate acyltransferase, and acetyl-CoA carboxylase by AMP-activated protein kinase in rat tissues in response to exercise. J. Biol. Chem. 277, 3257132577

51 Mclnnes, K.J., Corbould, A., Simpson, E.R., Jones, M.E. (2006) Regulation of adenosine 5',monophosphate-activated protein kinase and lipogenesis by androgens contributes to visceral obesity in an estrogen-deficient state. Endocrinology 147, 5907-5913

52 Vucetic, M., Otasevic, V., Korac, A., Stancic, A., Jankovic, A., Markelic, M., Golic, I., Velickovic, K., Buzadzic, B. and Korac, B. (2011) Interscapular brown adipose tissue metabolic reprogramming during cold acclimation: Interplay of HIF-1a and AMPKa. Biochim. Biophys, Acta. 1810, 1252-1261

53 Zhang, Q., Zhang, Y., Feng, H., Guo, R., Jin, L., Wan, R., Wang, L., Chen, C. and Li, S. (2011) High density lipoprotein (HDL) promotes glucose uptake in adipocytes and glycogen synthesis in muscle cells. PLoS One. 6, e23556

54 Wang, Z., Pini, M., Yao, T., Zhou, Z., Sun, C., Fantuzzi, G. and Song, Z. (2011) Homocysteine suppresses lipolysis in adipocytes by activating the AMPK pathway. Am J. Physiol. Endocrinol. Metab. 301, E703-E712

55 An, Z., Wang, H., Song, P., Zhang, M., Geng, X. and Zou, M.H. (2007) Nicotineinduced activation of AMP-activated protein kinase inhibits fatty acid synthase in 3T3L1 adipocytes: a role for oxidant stress. J. Biol. Chem. 282, 26793-26801

56 Lorente-Cebrián, S., Bustos, M., Marti, A., Martinez, J.A. and Moreno-Aliaga, M.J. (2009) Eicosapentaenoic acid stimulates AMP-activated protein kinase and increases visfatin secretion in cultured murine adipocytes. Clin. Sci. 117, 243-249

57 Gurriarán-Rodríguez, U., Al-Massadi, O., Roca-Rivada, A., Crujeiras, A.B., Gallego, R., Pardo, M., Seoane, L.M., Pazos, Y., Casanueva, F.F. and Camiña, J.P. (2011) Obestatin as a regulator of adipocyte metabolism and adipogenesis. J. Cell. Mol. Med. 15, 1927-1940

58 Mclnnes, K.J., Brown, K.A., Hunger, N.I. and Simpson, E.R. (2012) Regulation of LKB1 expression by sex hormones in adipocytes. Int. J. Obes. 36, 982-985

59 Liu, Q., Gauthier, M.S., Sun, L., Ruderman, N. and Lodish, H. (2010) Activation of AMP-activated protein kinase signaling pathway by adiponectin and insulin in mouse adipocytes: requirement of acyl-CoA synthetases FATP1 and Acsl1 and association with an elevation in AMP/ATP ratio. FASEB J.24, 4229-4239

60 Wang, M.Y., Orci, L., Ravazzola, M. and Unger, R.H. (2005) Fat storage in adipocytes requires inactivation of leptin's paracrine activity: implications for treatment of human obesity. Proc. Natl. Acad. Sci. U S A. 102, 18011-18016

61 Boyle, J.G., Logan, P.J., Jones, G.C., Small, M., Sattar, N., Connell, J.M., Cleland, S.J. and Salt, I.P. (2011) AMP-activated protein kinase is activated in adipose tissue of individuals with type 2 diabetes treated with metformin: a randomised glycaemiacontrolled crossover study. Diabetologia 54, 1799-1809

62 Caton, P.W., Kieswich, J., Yaqoob, M.M., Holness, M.J. and Sugden, M.C. (2011) Metformin opposes impaired AMPK and SIRT1 function and deleterious changes in core clock protein expression in white adipose tissue of genetically-obese $\mathrm{db} / \mathrm{db}$ mice. Diabetes. Obes. Metab. 13, 1097-1104 
63 Buhl, E.S., Jessen, N., Schmitz, O., Pedersen, S.B., Pedersen, O., Holman, G.D. and Lund, S. (2001) Chronic treatment with 5-aminoimidazole-4-carboxamide-1-beta-Dribofuranoside increases insulin-stimulated glucose uptake and GLUT4 translocation in rat skeletal muscles in a fiber type-specific manner. Diabetes 50, 12-17

64 Fisher, J.S., Gao, J., Han, D.H., Holloszy, J.O. and Nolte, L.A. (2002) Activation of AMP kinase enhances sensitivity of muscle glucose transport to insulin. Am. J. Physiol. Endocrinol. Metab. 282, E18-E23

65 Iglesias, M.A., Ye, J.M., Frangioudakis, G., Saha, A.K., Tomas, E., Ruderman, N.B., Cooney, G.J. and Kraegen, E.W. (2002) AICAR administration causes an apparent enhancement of muscle and liver insulin action in insulin-resistant high-fat-fed rats. Diabetes 51, 2886-2894

66 Ojuka, E.O., Jones, T.E., Nolte, L.A., Chen, M., Wamhoff, B.R., Sturek, M. and Holloszy, J.O. (2002) Regulation of GLUT4 biogenesis in muscle: evidence for involvement of AMPK and $\mathrm{Ca}(2+)$. Am. J. Physiol. Endocrinol. Metab. 282, E1008E1013

67 Koistinen, H.A., Galuska, D., Chibalin, A.V., Yang, J., Zierath, J.R., Holman, G.D. and Wallberg-Henriksson, H. (2003) 5-amino-imidazole carboxamide riboside increases glucose transport and cell-surface GLUT4 content in skeletal muscle from subjects with type 2 diabetes. Diabetes 52, 1066-1072

68 Kramer, H.F., Witczak, C.A., Fujii, N., Jessen, N., Taylor, E.B., Arnolds, D.E., Sakamoto, K., Hirshman, M.F. and Goodyear, L.J. (2006) Distinct signals regulate AS160 phosphorylation in response to insulin, AICAR, and contraction in mouse skeletal muscle. Diabetes 55, 2067-2076

69 Fazakerley, D.J., Holman, G.D., Marley, A., James, D.E., Stöckli, J. and Coster, A.C. (2009) Kinetic evidence for unique regulation of GLUT4 trafficking by insulin and AMP-activated protein kinase activators in L6 myotubes. J. Biol. Chem. 285, 16531660

70 Sakoda, H., Ogihara, T., Anai, M., Fujishiro, M., Ono, H., Onishi, Y., Katagiri, H., Abe, M., Fukushima, Y., Shojima, N., Inukai, K., Kikuchi, M., Oka, Y. and Asano, T. (2002) Activation of AMPK is essential for AICAR-induced glucose uptake by skeletal muscle but not adipocytes. Am. J. Physiol. Endocrinol. Metab. 282, E1239-E1244

71 Gaidhu, M.P., Fediuc, S. and Ceddia, R.B. (2006) 5-Aminoimidazole-4-carboxamide1-beta-D-ribofuranoside-induced AMP-activated protein kinase phosphorylation inhibits basal and insulin-stimulated glucose uptake, lipid synthesis, and fatty acid oxidation in isolated rat adipocytes. J. Biol. Chem. 281, 25956-25964

72 Gaidhu, M.P., Perry, R.L., Noor, F. and Ceddia, R.B. (2010) Disruption of AMPKalpha1 signaling prevents AICAR-induced inhibition of AS160/TBC1D4 phosphorylation and glucose uptake in primary rat adipocytes. Mol. Endocrinol. 24, 1434-1440

73 Wu, X., Motoshima, H., Mahadev, K., Stalker, T.J., Scalia, R. and Goldstein, B.J. (2003) Involvement of AMP-activated protein kinase in glucose uptake stimulated by the globular domain of adiponectin in primary rat adipocytes. Diabetes 52, 1355-1363

74 Bain, J., Plater, L., Elliott, M., Shpiro, N., Hastie, C.J., McLauchlan, H., Klevernic, I., Arthur, J.S., Alessi, D.R. and Cohen, P. (2007) The selectivity of protein kinase inhibitors: a further update. Biochem. J. 408, 297-315

75 Emerling, B.M., Viollet, B., Tormos, K.V. and Chandel, N.S. (2007) Compound C inhibits hypoxic activation of HIF-1 independent of AMPK. FEBS Lett. 581, 57275731

76 Kim, Y.M., Kim, M.Y., Kim, H.J., Roh, G.S., Ko, G.H., Seo, H.G., Lee, J.H. and Chang, K.C. (2011) Compound $C$ independent of AMPK inhibits ICAM-1 and VCAM1 expression in inflammatory stimulants-activated endothelial cells in vitro and in vivo. Atherosclerosis 219, 57-64 
77 Henin, N., Vincent, M.F. and Van den Berghe, G. (1996) Stimulation of rat liver AMPactivated protein kinase by AMP analogues. Biochim. Biophys. Acta. 1290, 197-203

78 Iwatsubo, K., Bravo, C., Uechi, M., Baljinnyam, E., Nakamura, T., Umemura, M., Lai, L., Gao, S., Yan, L., Zhao, X., Park, M., Qiu, H., Okumura, S., Iwatsubo, M., Vatner, D.E., Vatner, S.F. and Ishikawa, Y. (2012) Prevention of heart failure in mice by an antiviral agent that inhibits type 5 cardiac adenylyl cyclase. Am. J. Physiol. Heart. Circ. Physiol. 302, H2622-H2628

79 Reshef, L., Olswang, Y., Cassuto, H., Blum, B., Croniger, C.M., Kalhan, S.C., Tilghman, S.M. and Hanson, R.W. (2003) Glyceroneogenesis and the triglyceride/fatty acid cycle. J. Biol. Chem. 278, 30413-30416

80 Gaidhu, M.P., Fediuc, S., Anthony, N.M., So, M., Mirpourian, M., Perry, R.L. and Ceddia, R.B. (2009) Prolonged AICAR-induced AMP-kinase activation promotes energy dissipation in white adipocytes: novel mechanisms integrating HSL and ATGL. J. Lipid Res. 50, 704-71576

81 Sakamoto, K. and Holman, G.D. (2008) Emerging role for AS160/TBC1D4 and TBC1D1 in the regulation of GLUT4 traffic. Am. J. Physiol. Endocrinol. Metab. 295, E29-E37

82 Chavez, J.A., Roach, W.G., Keller, S.R., Lane, W.S. and Lienhard, G.E. (2008) Inhibition of GLUT4 translocation by Tbc1d1, a Rab GTPase-activating protein abundant in skeletal muscle, is partially relieved by AMP-activated protein kinase activation. J. Biol. Chem. 283, 9187-9195

83 Sano, H., Kane, S., Sano, E., Mîinea, C.P., Asara, J.M., Lane, W.S., Garner, C.W. and Lienhard, G.E. (2003) Insulin-stimulated phosphorylation of a Rab GTPaseactivating protein regulates GLUT4 translocation. J. Biol. Chem. 278, 14599-14602

84 Geraghty, K.M., Chen, S., Harthill, J.E., Ibrahim, A.F., Toth, R., Morrice, N.A., Vandermoere, F., Moorhead, G.B., Hardie, D.G. and MacKintosh, C. (2007) Regulation of multisite phosphorylation and 14-3-3 binding of AS160 in response to IGF-1, EGF, PMA and AICAR. Biochem. J. 407, 231-241

85 Chen, S., Murphy, J., Toth, R., Campbell, D.G., Morrice, N.A. and Mackintosh, C. (2008) Complementary regulation of TBC1D1 and AS160 by growth factors, insulin and AMPK activators. Biochem. J. 409, 449-459

86 Chen, S. and Mackintosh, C. (2009) Differential regulation of NHE1 phosphorylation and glucose uptake by inhibitors of the ERK pathway and p90RSK in 3T3-L1 adipocytes. Cell Signal. 21, 1984-1993

87 Perrotti, N., He, R.A., Phillips, S.A., Haft, C.R. and Taylor, S.I. (2001) Activation of serum- and glucocorticoid-induced protein kinase (Sgk) by cyclic AMP and insulin. J. Biol. Chem. 276, 9406-9412

88 Fischer, M., Timper, K., Radimerski, T., Dembinski, K., Frey, D.M., Zulewski, H., Keller, U., Müller, B., Christ-Crain, M. and Grisouard, J. (2010) Metformin induces glucose uptake in human preadipocyte-derived adipocytes from various fat depots. Diabetes Obes. Metab. 12, 356-359

89 Holmes, B.F., Kurth-Kraczek, E.J. and Winder, W.W. (1999) Chronic activation of 5'AMP-activated protein kinase increases GLUT-4, hexokinase, and glycogen in muscle. J. Appl. Physiol. 87, 1990-1995

90 Ojuka, E.O., Nolte, L.A. and Holloszy, J.O. (2000) Increased expression of GLUT-4 and hexokinase in rat epitrochlearis muscles exposed to AICAR in vitro. J. Appl. Physiol. 88, 1072-1075

91 Barnes, B.R., Long, Y.C., Steiler, T.L., Leng, Y., Galuska, D., Wojtaszewski, J.F., Andersson, L. and Zierath, J.R. (2005) Changes in exercise-induced gene expression in 5'-AMP-activated protein kinase gamma3-null and gamma3 R225Q transgenic mice. Diabetes 54, 3484-3489 
92 McGee, S.L., van Denderen, B.J., Howlett, K.F., Mollica, J., Schertzer, J.D., Kemp, B.E. and Hargreaves, M. (2008) AMP-activated protein kinase regulates GLUT4 transcription by phosphorylating histone deacetylase 5. Diabetes 57, 860-867

93 Polakof, S., Moon, T.W., Aguirre, P., Skiba-Cassy, S. and Panserat, S. (2011) Glucose homeostasis in rainbow trout fed a high-carbohydrate diet: metformin and insulin interact in a tissue-dependent manner. Am. J. Physiol. Regul. Integr. Comp. Physiol. 300, R166-R174

94 Lihn, A.S., Pedersen, S.B., Lund, S. and Richelsen, B. (2008) The anti-diabetic AMPK activator AICAR reduces IL-6 and IL-8 in human adipose tissue and skeletal muscle cells. Mol. Cell. Endocrinol. 292, 36-41

95 Ducharme, N.A. and Bickel, P.E. (2008) Lipid droplets in lipogenesis and lipolysis. Endocrinology 149, 942-949

96 Egan, J.J., Greenberg, A.S., Chang, M.K., Wek, S.A., Moos, M.C. Jr. and Londos, C. (1992) Mechanism of hormone-stimulated lipolysis in adipocytes: translocation of hormone-sensitive lipase to the lipid storage droplet. Proc. Natl. Acad. Sci. U S A. 89, 8537-8541

97 Chaves, V.E., Frasson, D. and Kawashita, N.H. (2011) Several agents and pathways regulate lipolysis in adipocytes. Biochimie 93, 1631-1640

98 Pagnon, J., Matzaris, M., Stark, R., Meex, R.C., Macaulay, S.L., Brown, W., O'Brien, P.E., Tiganis, T. and Watt, M.J. (2012) Identification and functional characterization of protein kinase a phosphorylation sites in the major lipolytic protein, adipose triglyceride lipase. Endocrinology 153, 4278-4289

99 Zimmermann, R., Strauss, J.G., Haemmerle, G., Schoiswohl, G., BirnerGruenberger, R., Riederer, M., Lass, A., Neuberger, G., Eisenhaber, F., Hermetter, A. and Zechner, R. (2004) Fat mobilization in adipose tissue is promoted by adipose triglyceride lipase. Science 306, 1383-1386

100 Ahmadian, M., Abbott, M.J., Tang, T., Hudak, C.S., Kim, Y., Bruss, M., Hellerstein, M.K., Lee, H.Y., Samuel, V.T., Shulman, G.I., Wang, Y., Duncan, R.E., Kang, C. and Sul, H.S. (2011) Desnutrin/ATGL is regulated by AMPK and is required for a brown adipose phenotype. Cell Metab. 13, 739-748

101 Duncan, R.E., Wang, Y., Ahmadian, M., Lu, J., Sarkadi-Nagy, E. and Sul, H.S. (2010) Characterization of desnutrin functional domains: critical residues for triacylglycerol hydrolysis in cultured cells. J. Lipid Res. 51, 309-317

102 Sullivan, J.E., Brocklehurst, K.J., Marley, A.E., Carey, F., Carling, D. and Beri, R.K. (1994) Inhibition of lipolysis and lipogenesis in isolated rat adipocytes with AICAR, a cell-permeable activator of AMP-activated protein kinase. FEBS Lett. 353, 33-36

103 Anthony, N.M., Gaidhu, M.P. and Ceddia, R.B. (2009) Regulation of visceral and subcutaneous adipocyte lipolysis by acute AICAR-induced AMPK activation. Obesity $17,1312-1317$

104 Yin, W., Mu, J. and Birnbaum, M.J. (2003) Role of AMP-activated protein kinase in cyclic AMP-dependent lipolysis In 3T3-L1 adipocytes. J. Biol. Chem. 278, 4307443080

105 Koh, H.J., Hirshman, M.F., He, H., Li, Y., Manabe, Y., Balschi, J.A. and Goodyear, L.J. (2007) Adrenaline is a critical mediator of acute exercise-induced AMP-activated protein kinase activation in adipocytes. Biochem. J. 403, 473-481

106 Vaughan, M. (1962) The production and release of glycerol by adipose tissue incubated in vitro. J. Biol. Chem. 237, 3354-3358

107 Reshef, L., Hanson, R.W. and Ballard, F.J. (1970) A possible physiological role for glyceroneogenesis in rat adipose tissue. J. Biol. Chem. 245, 5979-5984

108 Brooks, B., Arch, J.R. and Newsholme, E.A. (1982) Effects of hormones on the rate of the triacylglycerol/fatty acid substrate cycle in adipocytes and epididymal fat pads. FEBS Lett. 146, 327-330 
109 Gauthier, M.S., Miyoshi, H., Souza, S.C., Cacicedo, J.M., Saha, A.K., Greenberg, A.S. and Ruderman, N.B. (2008) AMP-activated protein kinase is activated as a consequence of lipolysis in the adipocyte: potential mechanism and physiological relevance. J. Biol. Chem. 283, 16514-16524

110 Bourron, O., Daval, M., Hainault, I., Hajduch, E., Servant, J.M., Gautier, J.F., Ferré, P. and Foufelle, F. (2010) Biguanides and thiazolidinediones inhibit stimulated lipolysis in human adipocytes through activation of AMP-activated protein kinase. Diabetologia. 53, 768-778

111 Flechtner-Mors, M., Ditschuneit, H.H., Jenkinson, C.P., Alt, A. and Adler, G. (1999) Metformin inhibits catecholamine-stimulated lipolysis in obese, hyperinsulinemic, hypertensive subjects in subcutaneous adipose tissue: an in situ microdialysis study. Diabet. Med. 16, 1000-1006

112 Zhang, T., He, J., Xu, C., Zu, L., Jiang, H., Pu, S., Guo, X. and Xu, G. (2008) Mechanisms of metformin inhibiting lipolytic response to isoproterenol in primary rat adipocytes. J. Mol. Endocrinol. 42, 57-66

113 Garton, A.J. and Yeaman, S.J. (1990) Identification and role of the basal phosphorylation site on hormone-sensitive lipase. Eur. J. Biochem. 191, 245-250

114 Su, C.L., Sztalryd, C., Contreras, J.A., Holm, C., Kimmel, A.R. and Londos, C. (2003) Mutational analysis of the hormone-sensitive lipase translocation reaction in adipocytes. J. Biol. Chem. 278, 43615-43619

115 Chakrabarti, P., English, T., Karki, S., Qiang, L., Tao, R., Kim, J., Luo, Z., Farmer, S.R. and Kandror, K.V. (2011) SIRT1 controls lipolysis in adipocytes via FOXO1mediated expression of ATGL. J. Lipid Res. 52, 1693-1701

116 Takekoshi, K., Fukuhara, M., Quin, Z., Nissato, S., Isobe, K., Kawakami, Y. and Ohmori, H. (2006) Long-term exercise stimulates adenosine monophosphateactivated protein kinase activity and subunit expression in rat visceral adipose tissue and liver. Metabolism 55, 1122-1128

117 Peng, I.C., Chen, Z., Sun, W., Li, Y.S., Marin, T.L., Hsu, P.H., Su, M.I., Cui, X., Pan, S., Lytle, C.Y., Johnson, D.A., Blaeser, F., Chatila, T. and Shyy, J.Y. (2012) Glucagon regulates ACC activity in adipocytes through the CAMKK $/ A M P K$ pathway. Am. J. Physiol. Endocrinol. Metab. 302, E1560-E1568

118 Orci, L., Cook, W.S., Ravazzola, M., Wang, M.Y., Park, B.H., Montesano, R. and Unger, R.H. (2004) Rapid transformation of white adipocytes into fat-oxidizing machines. Proc. Natl. Acad. Sci. U S A. 101, 2058-2063

119 Li, Y., Xu, S., Mihaylova, M.M., Zheng, B., Hou, X., Jiang, B., Park, O., Luo, Z., Lefai, E., Shyy, J.Y., Gao, B., Wierzbicki, M., Verbeuren, T.J., Shaw, R.J., Cohen, R.A. and Zang, M. (2011) AMPK phosphorylates and inhibits SREBP activity to attenuate hepatic steatosis and atherosclerosis in diet-induced insulin-resistant mice. Cell Metab. 13, 376-388

120 Giri, S., Rattan, R., Haq, E., Khan, M., Yasmin, R., Won, J.S., Key, L., Singh, A.K. and Singh, I. (2006) AICAR inhibits adipocyte differentiation in 3T3L1 and restores metabolic alterations in diet-induced obesity mice model. Nutr. Metab. 3, 31

121 Samovski, D., Su, X., Xu, Y., Abumrad, N.A. and Stahl, P.D. (2012) Insulin and AMPK regulate $\mathrm{FA}$ translocase/CD36 plasma membrane recruitment in cardiomyocytes via Rab GAP AS160 and Rab8a Rab GTPase. J. Lipid Res. 53, 709717

122 Schwenk, R.W., Dirkx, E., Coumans, W.A., Bonen, A., Klip, A., Glatz, J.F. and Luiken, J.J. (2010) Requirement for distinct vesicle-associated membrane proteins in insulin- and AMP-activated protein kinase (AMPK)-induced translocation of GLUT4 and CD36 in cultured cardiomyocytes. Diabetologia 53, 2209-2219 
123 Luo, B., Parker, G.J., Cooksey, R.C., Soesanto, Y., Evans, M., Jones, D. and McClain, D.A. (2007) Chronic hexosamine flux stimulates fatty acid oxidation by activating AMP-activated protein kinase in adipocytes. J. Biol. Chem. 282, 7172-7180

124 Gaidhu, M.P., Frontini, A., Hung, S., Pistor, K., Cinti, S. and Ceddia, R.B. (2011) Chronic AMP-kinase activation with AICAR reduces adiposity by remodeling adipocyte metabolism and increasing leptin sensitivity. J. Lipid Res. 52, 1702-1711

125 Winder, W.W., Holmes, B.F., Rubink, D.S., Jensen, E.B., Chen, M. and Holloszy, J.O. (2000) Activation of AMP-activated protein kinase increases mitochondrial enzymes in skeletal muscle. J. Appl. Physiol. 88, 2219-2226

126 Narkar, V.A., Downes, M., Yu, R.T., Embler, E., Wang, Y.X., Banayo, E., Mihaylova, M.M., Nelson, M.C., Zou, Y., Juguilon, H., Kang, H., Shaw, R.J. and Evans, R.M. (2008) AMPK and PPARdelta agonists are exercise mimetics. Cell 134, 405-415

127 MacDougald, O.A. and Lane, M.D. (1995) Transcriptional regulation of gene expression during adipocyte differentiation. Annu. Rev. Biochem. 64, 345-373

128 Rosen, E.D., Walkey, C.J., Puigserver, P. and Spiegelman, B.M. (2000) Transcriptional regulation of adipogenesis. Genes Dev. 14, 1293-1307

129 Grimaldi, C., Chiarini, F., Tabellini, G., Ricci, F., Tazzari, P.L., Battistelli, M., Falcieri, E., Bortul, R., Melchionda, F., Pagliaro, P., Martinelli, G., Pession, A., Barata, J.T., McCubrey, J.A. and Martinelli, A.M. (2012) AMP-dependent kinase/mammalian target of rapamycin complex 1 signaling in T-cell acute lympoblastic leukemia: therapeutic implications. Leukemia 26, 91-100

130 Peyton, K.J., Lui, X.M., Yu, Y., Yates, B. and Durante, W. (2012) Activation of AMPactivated protein kinase inhibits the proliferation of human endothelial cells. J. Pharmacol. Exp. Ther. 342, 827-834

131 Imamura, K., Ogura, T., Kishimoto, A., Kaminishi, M. and Esumi, H. (2001) Cell cycle regulation via p53 phosphorylation by a 5'-AMP activated protein kinase activator, 5aminoimidazole- 4-carboxamide-1-beta-D-ribofuranoside, in a human hepatocellular carcinoma cell line. Biochem. Biophys. Res. Commun. 287, 562-567

132 Habinowski, S.A and Witters, L.A. (2001) The effect of AICAR on adipocyte differentiation of 3T3-L1 cells. Biochem. Biophys. Res. Commun. 286, 852-856

133 Vingtdeux, V., Chandakkar, P., Zhao, H., Davies, P. and Marambaud, P. (2011) Mol Med. 17, 1022-1030

134 Lee, H., Kang, R., Bae, S. and Yoon, Y. (2011) AICAR, an activator of AMPK, inhibits adipogenesis via the WNT/ $\beta$-catenin pathway in 3T3-L1 adipocytes. Int. J. Mol. Med. 28, 65-71

135 Lin, F., Ribar, T.J. and Means, A.R. (2011) The Ca2+/calmodulin-dependent protein kinase kinase, CaMKK2, inhibits preadipocyte differentiation. Endocrinology 152, 3668-3679

136 Villena, J.A., Viollet, B., Andreelli, F., Kahn, A., Vaulont, S. and Sul, H.S. (2004) Induced adiposity and adipocyte hypertrophy in mice lacking the AMP-activated protein kinase-alpha2 subunit. Diabetes 53, 2242-2249

137 Zhang, W., Zhang, X., Wang, H., Guo, X., Li, H., Wang, Y., Xu, X., Tan, L., Mashek, M.T., Zhang, C., Chen, Y., Mashek, D.G., Foretz, M., Zhu, C., Zhou, H., Liu, X., Viollet, B., Wu, C. and Huo, Y. (2012) AMP-activated protein kinase a1 protects against diet-induced insulin resistance and obesity. Diabetes in press

138 Lönnqvist, F., Nordfors, L., Jansson, M., Thörne, A., Schalling, M. and Arner, P. (1997) Leptin secretion from adipose tissue in women. Relationship to plasma levels and gene expression. J. Clin. Invest. 99, 2398-2404

139 Coppari, R. and Bjørbæk, C. (2012) Leptin revisited: its mechanism of action and potential for treating diabetes. Nat. Rev. Drug. Discov. 11, 692-708

140Barré, L., Richardson, C., Hirshman, M.F., Brozinick, J., Fiering, S., Kemp, B.E., Goodyear, L.J. and Witters, L.A. (2007) Genetic model for the chronic activation of 
skeletal muscle AMP-activated protein kinase leads to glycogen accumulation. Am. J. Physiol. Endocrinol. Metab. 292, E802-E811

141 Arita, Y., Kihara, S., Ouchi, N., Takahashi, M., Maeda, K., Miyagawa, J., Hotta, K., Shimomura, I., Nakamura, T., Miyaoka, K., Kuriyama, H., Nishida, M., Yamashita, S., Okubo, K., Matsubara, K., Muraguchi, M., Ohmoto, Y., Funahashi, T. and Matsuzawa, Y. (1999) Paradoxical decrease of an adipose-specific protein, adiponectin, in obesity. Biochem. Biophys. Res. Commun. 257, 79-83

142Turer, A.T. and Scherer, P.E. (2012) Adiponectin: mechanistic insights and clinical implications. Diabetologia 55, 2319-2326

143 Gustafson, B. (2010) Adipose tissue, inflammation and atherosclerosis. J. Atheroscler. Thromb. 17, 332-341

144 Cinti, S., Mitchell, G., Barbatelli, G., Murano, I., Ceresi, E., Faloia, E., Wang, S., Fortier, M., Greenberg, A.S. and Obin, M.S. (2005) Adipocyte death defines macrophage localization and function in adipose tissue of obese mice and humans. J. Lipid Res. 46, 2347-2355

145 Jiao, P., Chen, Q., Shah, S., Du, J., Tao, B., Tzameli, I., Yan, W. and Xu, H. Obesityregulated upregulation of monocyte chemotactic factors in adipocytes: involvement of nuclear factor-kappaB and c-Jun NH2-terminal kinase pathways. Diabetes 58, 104115

146 Kanda, H., Tateya, S., Tamori, Y., Kotani, K., Hiasa, K., Kitazawa, R., Kitazawa, S., Miyachi, H., Maeda, S., Egashira, K. and Kasuga, M. (2006) MCP-1 contributes to macrophage infiltration into adipose tissue, insulin resistance, and hepatic steatosis in obesity. J. Clin. Invest. 116, 1494-1505

147 Kitade, H., Sawamoto, K., Nagashimada, M., Inoue, H., Yamamoto, Y., Sai, Y., Takamura, T., Yamamoto, H., Miyamoto, K., Ginsberg, H.N., Mukaida, N., Kaneko, S. and Ota, T. (2012) CCR5 plays a critical role in obesity-induced adipose tissue inflammation and insulin resistance by regulating both macrophage recruitment and M1/M2 status. Diabetes 61, 1680-1690

148 Nguyen, M.T., Favelyukis, S., Nguyen, A.K., Reichart, D., Scott, P.A., Jenn, A., LiuBryan, R., Glass, C.K., Neels, J.G. and Olefsky J.M. (2007) A subpopulation of macrophages infiltrates hypertrophic adipose tissue and is activated by free fatty acids via toll-like receptors 2 and 4 and JNK-dependent pathways. J. Biol. Chem. 282, 35279-35292

149 Arkan, M.C., Hevener, A.L., Greten, F.R., Maeda, S., Li, Z.W., Long, J.M., WynshawBoris, A., Poli, G., Olefsky, J. and Karin, M. (2005) Nat. Med. 11, 191-198

150 Hevener, A.L., Olefsky, J.M., Reichart, D., Nguyen, M.T., Bandyopadyhay, G., Leung, H.Y., Watt, M.J., Benner, C., Febbraio, M.A., Nguyen, A.K., Folian, B., Subramaniam, S., Gonzalez, F.J., Glass, C.K. and Ricote, M. (2007) Macrophage PPAR gamma is required for normal skeletal muscle and hepatic insulin sensitivity and full antidiabetic effects of thiazolidinediones. J. Clin. Invest. 117, 1658-1669

151 Odegaard, J.I., Ricardo-Gonzalez, R.R., Goforth, M.H., Morel, C.R., Subramanian, V., Mukundan, L., Red Eagle, A., Vats, D., Brombacher, F., Ferrante, A.W. and Chawla, A. (2007) Macrophage-specific PPARgamma controls alternative activation and improves insulin resistance. Nature 447, 1116-1120

152 Solinas, G., Vilcu, C., Neels, J.G., Bandyopadhyay, G.K., Luo, J.L., Naugler, W., Grivennikov, S., Wynshaw-Boris, A., Scadeng, M., Olefsky, J.M and Karin, M. (2007) JNK1 in hematopoietically derived cells contributes to diet-induced inflammation and insulin resistance without affecting obesity. Cell Metab. 6, 386-397

153 Nishimura, S., Manabe, I., Nagasaki, M., Hosoya, Y., Yamashita, H., Fujita, H., Ohsugi, M., Tobe, K., Kadowaki, T., Nagai, R. and Sugiura, S. (2007) Adipogenesis in obesity requires close interplay between differentiating adipocytes, stromal cells, and blood vessels. Diabetes 56, 1517-1526 
154 Nishimura, S., Manabe, I., Nagasaki, M., Seo, K., Yamashita, H., Hosoya, Y., Ohsugi, M., Tobe, K., Kadowaki, T., Nagai, R. and Sugiura, S. (2008) In vivo imaging in mice reveals local cell dynamics and inflammation in obese adipose tissue. J. Clin. Invest. 118, 710-721

155 Shi, H., Kokoeva, M.V., Inouye, K., Tzameli, I., Yin, H. and Flier, J.S. (2006) TLR4 links innate immunity and fatty acid-induced insulin resistance. J. Clin. Invest. 116, 3015-3025

156 Saberi, M., Woods, N.B., de Luca, C., Schenk, S., Lu, J.C., Bandyopadhyay, G., Verma, I.M. and Olefsky, J.M. (2009) Hematopoietic cell-specific deletion of tolllike receptor 4 ameliorates hepatic and adipose tissue insulin resistance in high-fatfed mice. Cell Metab. 10, 419-429

157 Vandanmagsar, B., Youm, Y.H., Ravussin, A., Galgani, J.E., Stadler, K., Mynatt, R.L., Ravussin, E., Stephens, J.M. and Dixit, V.D. (2011) The NLRP3 inflammasome instigates obesity-induced inflammation and insulin resistance. Nat. Med. 17, 179188

158 Jeong, H.W., Hsu, K.C., Lee, J.W., Ham, M., Huh, J.Y., Shin, H.J., Kim, W.S. and Kim, J.B. (2009) Berberine suppresses proinflammatory responses through AMPK activation in macrophages. Am. J. Physiol. Endocrinol. Metab. 296, E955E964

159 Sag, D., Carling, D., Stout, R.D. and Suttles, J. (2008) Adenosine 5'-monophosphateactivated protein kinase promotes macrophage polarization to an anti-inflammatory functional phenotype. J. Immunol. 181, 8633-8641

160 Lee, H.M., Kim, J.J., Kim, H.J., Shong, M., Ku, B.J. and Jo, E.K. (2012) Upregulated NLRP3 inflammasome activation in patients with type 2 diabetes. Diabetes in the press

161 Vats, D., Mukundan, L., Odegaard, J.I., Zhang, L., Smith, K.L., Morel, C.R., Wagner, R.A., Greaves, D.R., Murray, P.J. and Chawla, A. (2006) Oxidative metabolism and PGC-1beta attenuate macrophage-mediated inflammation. Cell Metab. 4, 13-24

162 Kohlstedt, K., Trouvain, C., Namgaladze, D. and Fleming, I. (2011) Adipocyte-derived lipids increase angiotensin-converting enzyme (ACE) expression and modulate macrophage phenotype. Basic Res. Cardiol. 106, 205-215

163 Jeon, B.T., Jeong, E.A., Shin, H.J., Lee, Y., Lee, D.H., Kim, H.J., Kang, S.S., Cho, G.J., Choi, W.S. and Roh, G.S. (2012) Resveratrol attenuates obesity-associated peripheral and central inflammation and improves memory deficit in mice fed a highfat diet. Diabetes 61, 1444-1454

164 Huypens, P., Quartier, E., Pipeleers, D. and Van de Casteele, M. (2005) Metformin reduces adiponectin protein expression and release in 3T3-L1 adipocytes involving activation of AMP activated protein kinase. Eur. J. Pharmacol. 518, 90-95

165 Rasmussen, M.S., Lihn, A.S., Pedersen, S.B., Bruun, J.M., Rasmussen, M. and Richelsen, B. (2006) Adiponectin receptors in human adipose tissue: effects of obesity, weight loss, and fat depots. Obesity 14, 28-35

166 Tang, X.X., Chen, H., Yu, S., Zhang, L., Caplan, M.J. and Chan, H.C. (2005) Lymphocytes accelerate epithelial tight junction assembly: role of AMP-activated protein kinase (AMPK). P.L.o.S. One 5, e12343

167 Steinberg, G.R., Michell, B.J., van Denderen, B.J., Watt, M.J., Carey, A.L., Fam, B.C., Andrikopoulos, S., Proietto, J., Görgün, C.Z., Carling, D., Hotamisligil, G.S., Febbraio, M.A., Kay, T.W. and Kemp, B.E. (2006) Tumor necrosis factor alphainduced skeletal muscle insulin resistance involves suppression of AMP-kinase signaling. Cell Metab. 4, 465-474

168 Kelly, M., Keller, C., Avilucea, P.R., Keller, P., Luo, Z., Xiang, X., Giralt, M., Hidalgo, J., Saha, A.K., Pedersen, B.K. and Ruderman, N.B. (2004) AMPK activity is 
diminished in tissues of IL- 6 knockout mice: the effect of exercise. Biochem. Biophys. Res. Commun. 320, 449-454

169 Carey, A.L., Steinberg, G.R., Macaulay, S.L., Thomas, W.G., Holmes, A.G., Ramm, G., Prelovsek, O., Hohnen-Behrens, C., Watt, M.J., James, D.E., Kemp, B.E., Pedersen, B.K. and Febbraio, M.A. (2006) Interleukin-6 increases insulinstimulated glucose disposal in humans and glucose uptake and fatty acid oxidation in vitro via AMP-activated protein kinase. Diabetes 55, 2688-2697

170 Yuen, D.Y., Dwyer, R.M., Matthews, V.B., Zhang, L., Drew, B.G., Neill, B., Kingwell, B.A., Clark, M.G., Rattigan, S. and Febbraio, M.A. (2009) Interleukin-6 attenuates insulin-mediated increases in endothelial cell signaling but augments skeletal muscle insulin action via differential effects on tumor necrosis factor-alpha expression. Diabetes 58, 1086-1095

171 Wan, Z., Ritchie, I., Beaudoin, M.S., Castellani, L., Chan, C.B. and Wright, D.C. (2012) IL-6 indirectly modulates the induction of glyceroneogenic enzymes in adipose tissue during exercise. P.L.o.S. One 7, e41719

172 Sakaue, H., Nishizawa, A., Ogawa, W., Teshigawara, K., Mori, T., Takashima, Y., Noda, T. and Kasuga, M. (2003) Requirement for 3-phosphoinositide-kependent dinase-1 (PDK-1) in insulin-induced glucose uptake in immortalized brown adipocytes. J. Biol. Chem. 278, 38870-38874

173 Hutchinson, D.S., Chernogubova, E., Dallner, O.S., Cannon, B. and Bengtsson, T. (2005) Beta-adrenoceptors, but not alpha-adrenoceptors, stimulate AMP-activated protein kinase in brown adipocytes independently of uncoupling protein-1. Diabetologia 48, 2386-2395

174 Pulinilkunnil, T., He, H., Kong, D., Asakura, K., Peroni, O.D., Lee, A. and Kahn, B.B. (2011) Adrenergic regulation of AMP-activated protein kinase in brown adipose tissue in vivo. J. Biol. Chem. 286, 8798-8809

175 Vila-Bedmar, R., Lorenzo, M. and Fernández-Veledo, S. (2010) Adenosine 5'monophosphate-activated protein kinase-mammalian target of rapamycin cross talk regulates brown adipocyte differentiation. Endocrinology 151, 980-992

176 Bauwens, J.D., Schmuck, E.G., Lindholm, C.R., Ertel, R.L., Mulligan, J.D., Hovis, I., Viollet, B. and Saupe, K.W. (2011) Cold tolerance, cold-induced hyperphagia, and nonshivering thermogenesis are normal in a1-AMPK-/- mice. Am. J. Physiol. Regul. Integr. Comp. Physiol. 301, R473-R483

177 Kristensen, J.M., Johnsen, A.B., Birk, J.B., Nielsen, J.N., Jensen, B.R., Hellsten, Y., Richter, E.A. and Wojtaszewski, J.F. (2007) Absence of humoral mediated 5'AMPactivated protein kinase activation in human skeletal muscle and adipose tissue during exercise. J. Physiol. 585, 897-909

178 Martínez-Agustin, O., Hernández-Morante, J.J., Martínez-Plata, E., Sánchez de Medina, F. and Garaulet, M. (2010) Differences in AMPK expression between subcutaneous and visceral adipose tissue in morbid obesity. Regul. Pept. 163, 31-36

179 Gauthier, M.S., O'Brien, E.L., Bigornia, S., Mott, M., Cacicedo, J.M., Xu, X.J., Gokce, N., Apovian, C. and Ruderman, N. (2011) Decreased AMP-activated protein kinase activity is associated with increased inflammation in visceral adipose tissue and with whole-body insulin resistance in morbidly obese humans. Biochem. Biophys. Res. Commun. 404, 382-387

180 Xu, X.J., Gauthier, M.S., Hess, D.T., Apovian, C.M., Cacicedo, J.M., Gokce, N., Farb, M., Valentine, R.J. and Ruderman, N.B. (2012) Insulin sensitive and resistant obesity in humans: AMPK activity, oxidative stress, and depot-specific changes in gene expression in adipose tissue. J. Lipid. Res. 53, 792-801

181 Kola, B., Christ-Crain, M., Lolli, F., Arnaldi, G., Giacchetti, G., Boscaro, M., Grossman, A.B. and Korbonits M (2008) Changes in adenosine 5'-monophosphate- 
activated protein kinase as a mechanism of visceral obesity in Cushing's syndrome. J. Clin. Endocrinol. Metab. 93, 4969-4973 


\section{FIGURE LEGENDS}

FIGURE 1

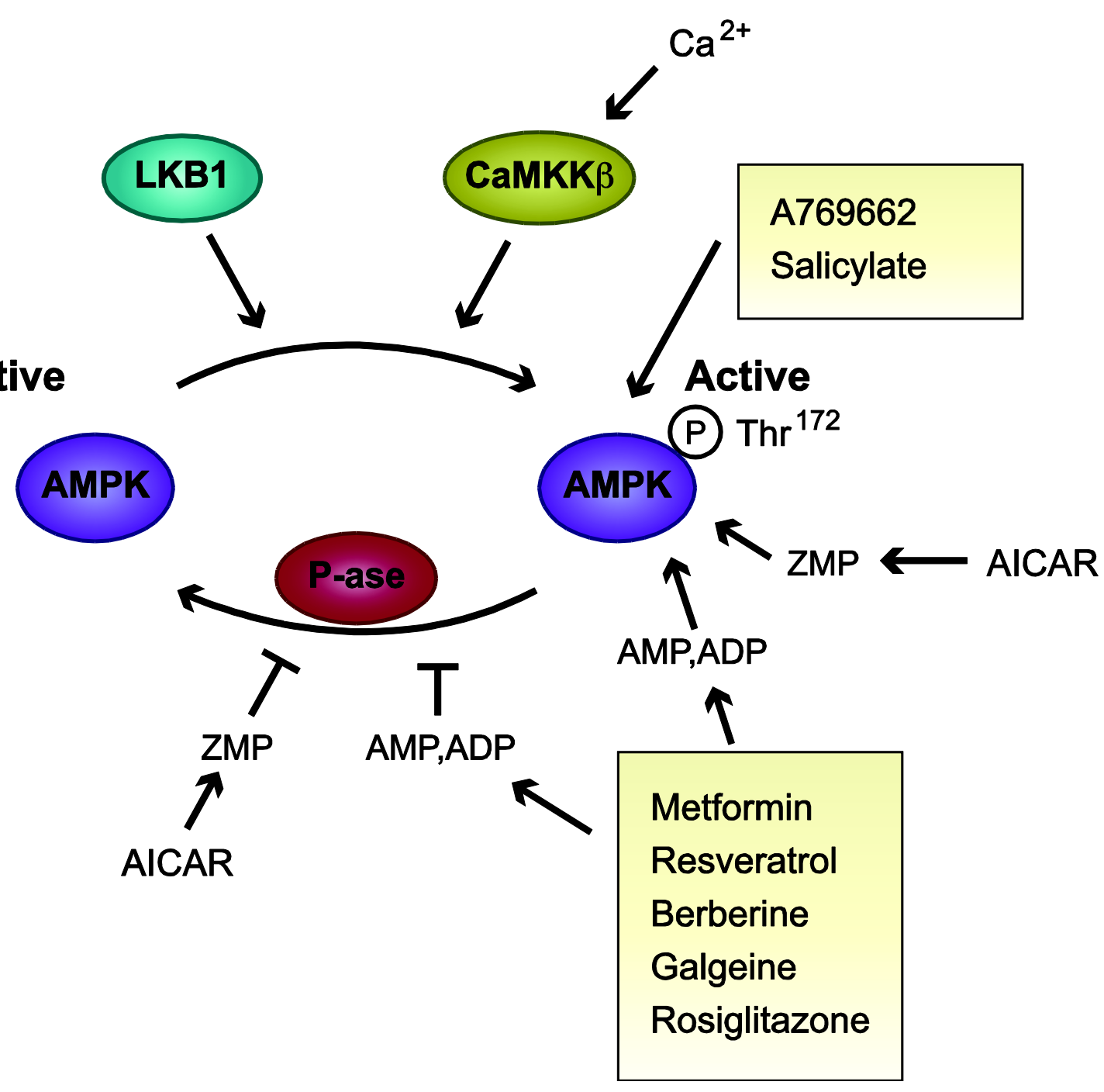

Figure 1 Regulation of AMPK.

AMPK is activated by phosphorylation of the $\alpha$ catalytic subunit at Thr172 by LKB1 or CaMKK $\beta$. Increased AMP or ADP concentrations (relative to ATP) bind to the regulatory $\gamma$ subunit, allosterically activating AMPK and inhibiting dephosphorylation of Thr172 by an as yet uncharacterised protein phosphatase (P-ase). Neither LKB1 nor CaMKK $\beta$ are regulated directly by adenine nucleotides. Increased intracellular $\mathrm{Ca}^{2+}$ stimulates CaMKK $\beta$-mediated AMPK activation independent of changes in adenine nucleotide ratios. The antidiabetic drugs metformin and rosiglitazone (thiazolidinedione) increase AMP:ATP or ADP:ATP concentrations, thereby activating AMPK. The plant-derived compounds resveratrol, galgeine and berberine also activate AMPK by this mechanism. AICAR is phosphorylated to the nucleotide ZMP, which mimics AMP, thereby activating AMPK without altering adenine nucleotide ratios. A769662 and salicylate are reported to activate AMPK complexes containing the $\beta 1$ regulatory subunit directly. 


\section{FIGURE 2}

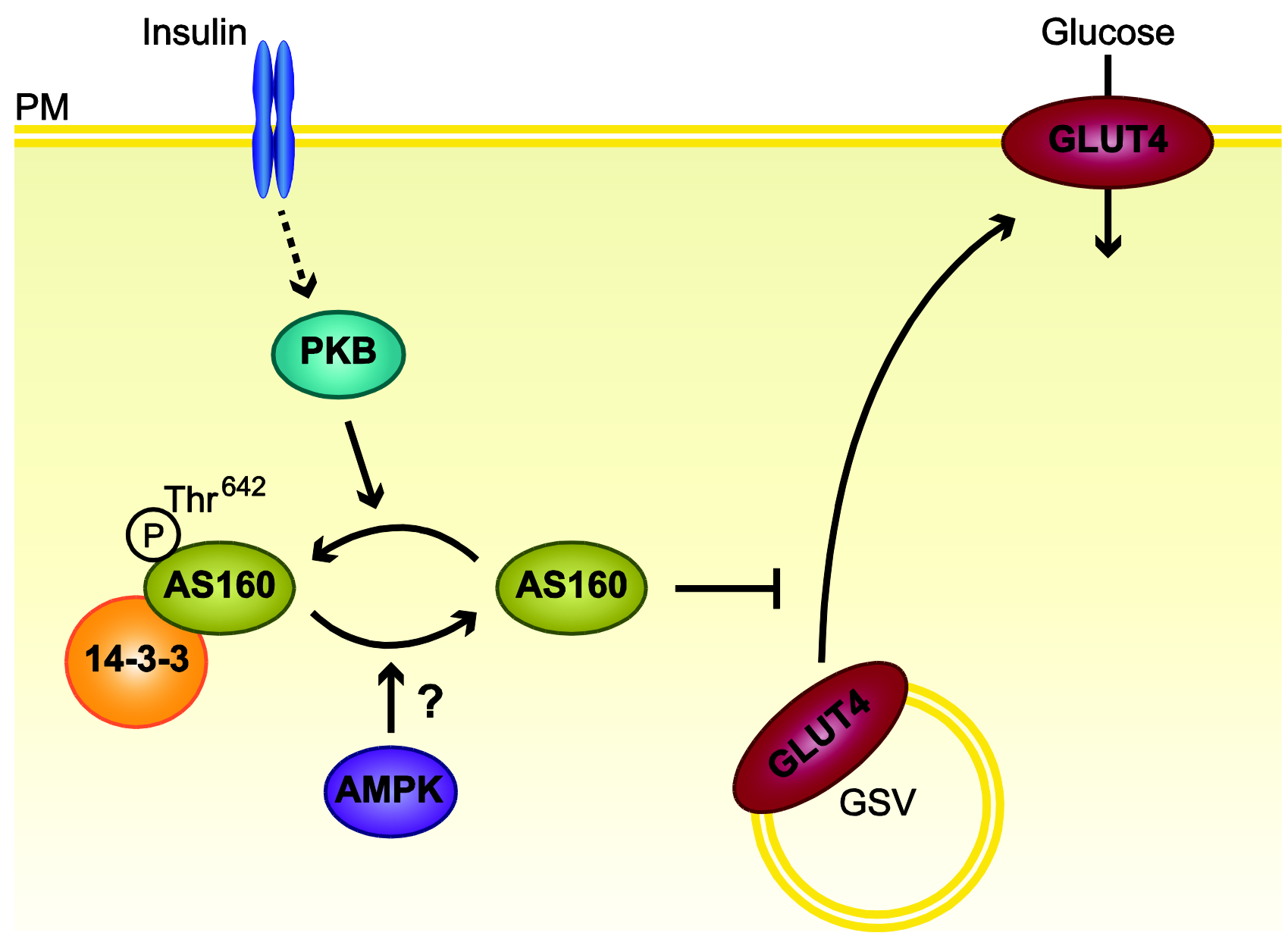

Figure 2 Regulation of insulin stimulated GLUT4 translocation in adipocytes by AMPK.

Insulin binding to the insulin receptor results in activation of PKB which in turn phosphorylates AS160 at Thr642. This enhances 14-3-3 binding to AS160 and inhibits AS160 Rab-GAP activity permitting GLUT4 to translocate from GLUT4 storage vesicles (GSV) to the plasma membrane (PM). The substantial increase in GLUT4 at the plasma membrane increases glucose transport. Activated AMPK has been reported to reduce insulin-stimulated Thr642 phosphorylation and 14-3-3 binding to AS160 although the mechanism by which this occurs remains uncertain. 


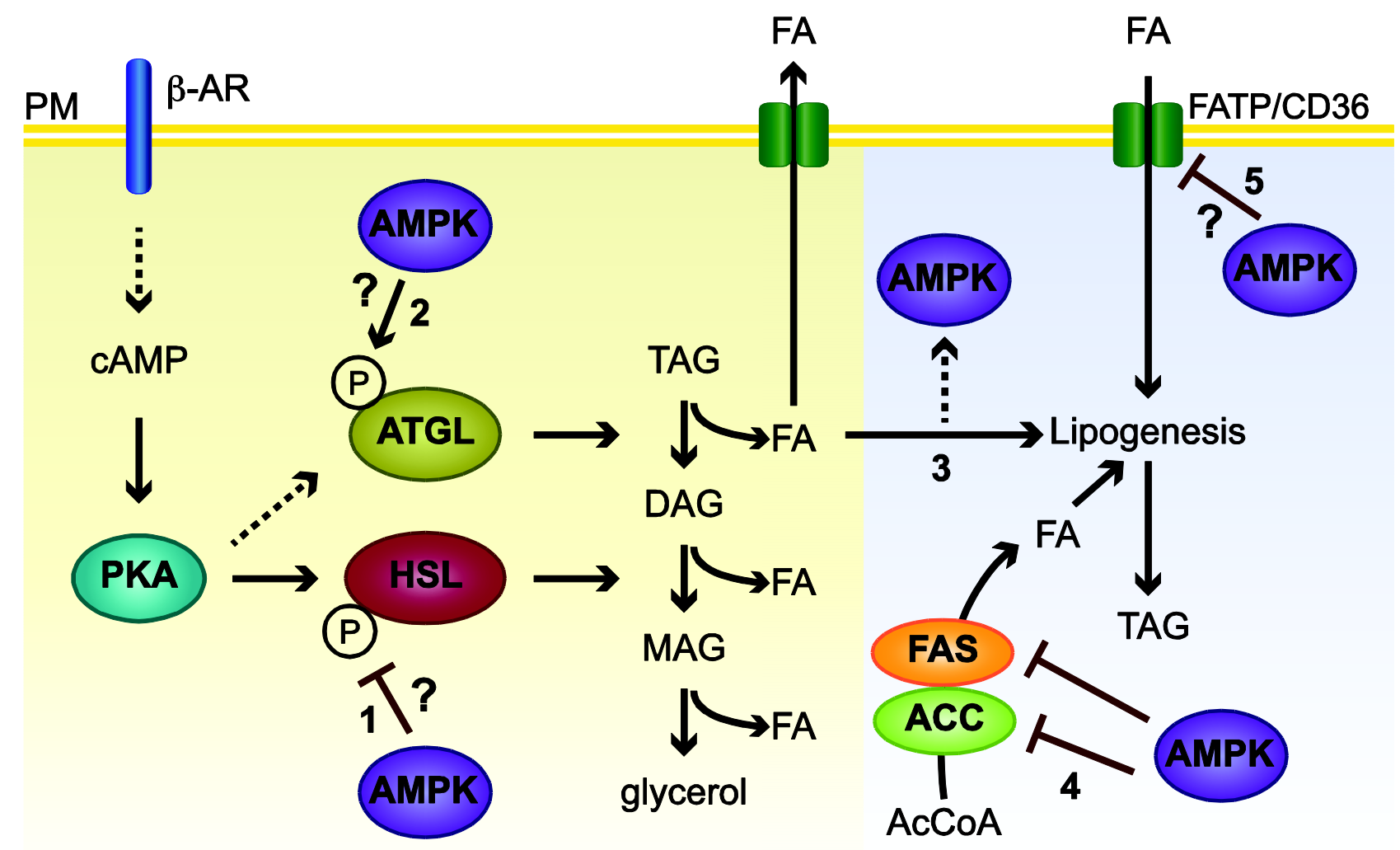

\section{Lipolysis}

\section{Lipogenesis}

Figure 3 Regulation of adipocyte lipid metabolism by AMPK.

Lipolysis is stimulated by $\beta$-adrenergic receptor ( $\beta$-AR)-mediated stimulation of cAMP production, resulting in PKA activation. PKA phosphorylates HSL and ATGL, increasing lipolysis, although whether ATGL phosphorylation by PKA in vivo remains uncertain. AMPK activation has been reported to influence lipolysis by (1) phosphorylation of HSL at Ser565, thereby preventing PKA-mediated HSL phosphorylation at Ser563 and subsequent lipolysis; (2) phosphorylation and activation of ATGL, thereby stimulating lipolysis. ATP-consumption during re-esterification of FAs after lipolysis may also activate AMPK (3), such that regulation of lipolysis by AMPK is likely to be dependent on the duration and mode of AMPK activation. AMPK phosphorylates and inactivates ACC in adipocytes, reducing FA synthesis and may inhibit the expression of ACC and FAS genes (4). It has also been suggested that AMPK activity inhibits FA oxidation due to reduced FA transport (5), mediated by FA transporters including CD36/FATP, yet this remains to be examined in adipocytes. 

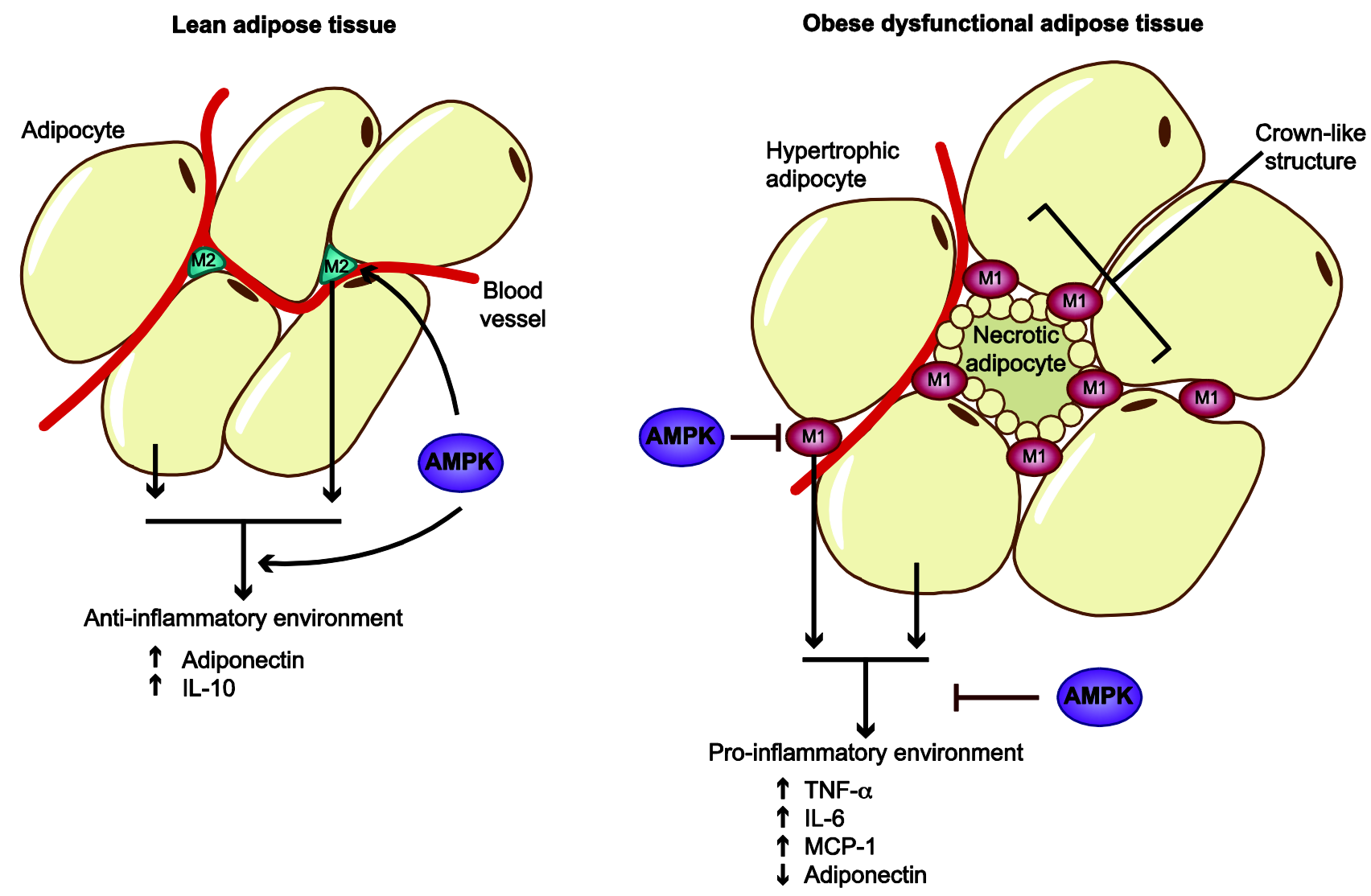

Figure 4 Anti-inflammatory actions of AMPK in adipose tissue.

In lean adipose tissue, small adipocytes and alternatively activated macrophages secrete adipocytokines such as $\mathrm{IL}-10$ and adiponectin, which maintain an anti-inflammatory environment. Production of these adipocytokines is promoted by activated AMPK. Excess calorie intake leads to the development of a pro-inflammatory environment within obese adipose tissue. Adipocytes enlarge, becoming hypertrophic and often necrotic, and there is an increased infiltration of macrophages. The proinflammatory environment drives macrophage polarisation towards the classically activated M1 state, and they tend to accumulate around necrotic adipocytes, forming crown-like structures. The secretory products of the macrophages and hypertrophic adipocytes further exacerbate this inflammation. Adipose tissue inflammation is linked to obesity-related insulin resistance and type 2 diabetes. Activation of AMPK can inhibit production of proinflammatory cytokines and chemokines, increase adiponectin secretion and inhibit macrophage recruitment and M1 polarisation, thereby potentially reducing insulin resistance. 